\title{
Measuring euro area monetary policy
}

\section{Carlo Altavilla ${ }^{\mathrm{a}, *}$, Luca Brugnolini ${ }^{\mathrm{b}}$, Refet S. Gürkaynak ${ }^{\mathrm{c}, \mathrm{d}}$, Roberto Motto ${ }^{\mathrm{e}}$, Giuseppe Ragusa ${ }^{\mathrm{f}}$}

a European Central Bank, 60314 Frankfurt am Main, Germany

${ }^{\mathrm{b}}$ Unaffiliated, London, UK

${ }^{\mathrm{c}}$ Department of Economics, Bilkent University, Ankara 06800, Turkey

${ }^{\mathrm{d}}$ Bilkent University, CEPR, CESIfo, E' CFS, Turkey

e European Central Bank, 60314 Frankfurt am Main, Germany

${ }^{\mathrm{f}}$ Department of Economics and Management, University of Pisa, Pisa 56124, Italy

\section{A R T I C L E I N F O}

\section{Article history:}

Received 21 August 2019

Accepted 21 August 2019

Available online 30 August 2019

\section{JEL classification:}

E43

E44

E52

E58

G12

Keywords:

G14 ECB Policy surprise

Event-study

Intraday

Persistence

Asymmetry

\begin{abstract}
A B S T R A C T
We map ECB policy communication into yield curve changes and study the information flow on policy dates. A byproduct is the publicly available Euro Area Monetary Policy Event-Study Database (EA-MPD), containing intraday asset price changes. We find that Policy Target, Forward Guidance and Quantitative Easing factors capture about all the variation in the yield curve, with different factors appearing in the windows covering the policy decision announcement and the press conference, and having time-varying variance shares. We study sovereign yields, exchange rates, stock prices, persistence of effects and response asymmetry. Our methodology can be implemented for any policy-related event.
\end{abstract}

(c) 2020 The Authors. Published by Elsevier B.V. This is an open access article under the CC BY license. (http://creativecommons.org/licenses/by/4.0/)

\section{Introduction}

Monetary policy, for better or worse, has been on the forefront of cyclical policymaking in the past two decades, especially during the Great Recession and the sovereign debt crisis. While there is an extensive literature on the US monetary policy, a comprehensive understanding of the ECB policy and its financial market effects are yet to materialize. This is partly due to the lack of a systematic database of high frequency, intraday data for a broad class of asset prices in the euro area of the kind that has been employed in the US for more than a decade.

\footnotetext{
मे We thank Burcin Kısacıkoğlu, Sang Seok Lee, Kadir Özen, Giulio Nicoletti, Michael McMahon, Giovanni Ricco, and Jonathan Wright for comments. Gürkaynak's research was supported by funding from the European Research Council (ERC) under the European Union's Horizon 2020 research and innovation program (grant agreement No. 726400). The database introduced in this paper is available at https://www.ecb.europa.eu/pub/pdf/annex/ Dataset_EA-MPD.xlsx and will be periodically updated by the authors. The code that implements the analysis is also available. The views expressed in this paper are those of the authors and do not necessarily reflect those of the European Central Bank or the Eurosystem.

* Corresponding author.

E-mail addresses: carlo.altavilla@ecb.europa.eu, carlo.altavilla@ecb.int (C. Altavilla), lucabrugnolini@gmail.com (L. Brugnolini), refet@bilkent.edu.tr (R.S. Gürkaynak), roberto.motto@ecb.europa.eu (R. Motto), giuseppe.ragusa@unipi.it (G. Ragusa).
} 
This paper helps remedy both deficiencies by constructing a long (by euro area standards) time series of policy-date event studies for the euro area, which will be kept up to date, and by using this data to measure and assess the ECB monetary policy. While our substantive analysis focuses on the financial market effects of monetary policy in the euro area, the dataset we construct to carry out the analysis is of independent interest. Our euro area monetary policy event-study database (EA-MPD) features price changes for a broad class of assets and various maturities, including Overnight Index Swaps (OIS), sovereign yields, stock prices, and exchange rates. We have exercised considerable care in studying each event window to clean outliers and misquotes, of which there were plenty early in the sample, to make sure that what we report accurately reflects the market reaction. We provide a description of the data, and timing of events on ECB policy dates in Section 2 and offer details and event-by-event analysis in an accompanying online appendix.

Monetary policy surprises in the euro area are not only multi-dimensional - we show the existence of perceived policy Target, Timing, Forward Guidance, and Quantitative Easing (QE) surprises - they are also revealed in a multi-step structure. A press release provides information on the policy decision with no rationale and discussion, later followed by a press conference. The information markets extract from these two events are distinct, and intraday data allows us to measure these different types of information separately. Our event-study database utilizes the intraday data to form event windows bracketing about $10 \mathrm{~min}$ before the release of monetary policy information, to about 10 min after. Employing tick data allows us to separately compute asset price changes around the release of the monetary policy decision at 13.45 , and the reading of the statement and the following $\mathrm{Q} \& \mathrm{~A}$ in the press conference beginning at 14.30 . The separate releases of the policy decision and the narrative information differentiates euro area monetary policy information revelation from that of the US, where the two happen simultaneously.

After briefly presenting the event-study database, we use it to study monetary policy surprises in the euro area and their effects on various financial market segments. To do so, we employ the methods developed by Gürkaynak et al. (2005) and Swanson (2017) for the US and use them in the two intraday windows of the euro area policy communication. The difference in the nature of information released in these two windows provides a new understanding of market participants' interpretation of monetary policy communication.

Our results show that, naturally, the preponderance of surprises in the press release window are about the current setting of the policy rates, "Target" surprises, with no other statistically significant policy surprise factors. In the press conference window, as expected, there are no Target surprises and the Path and QE surprises dominate. Interestingly, while our analysis suggests that a Target factor does not even appear as a statistically significant factor in the press conference window, a different factor, "Timing" emerges. This type of surprise captures the revision of policy expectations by shifting the expected policy action between the current meeting and the next or the one following, in a way that leaves longer-term policy expectations about unchanged. In essence, market participants extract two distinct types of guidance from the press conference. One that is informative about the medium run, peaking at about two years-Forward Guidance-and one for the near future, peaking at about six months maturity - what we call Timing.

The methodology we employ to extract QE surprises yields continuous measures of the market surprise. Hence, in studying the asset price responses to $\mathrm{QE}$, we are able to condition on the size of the surprises rather than only on a binary variable that shows when a $\mathrm{QE}$ announcement took place. This allows for a substantially more precise understanding of $\mathrm{QE}$ effects and helps distinguish QE from Forward Guidance surprises, which were also frequent during the Zero Lower Bound (ZLB) period. ${ }^{1}$ We find that both QE (after 2014) and Forward Guidance surprises are active in the press conference window and that while Forward Guidance affected the middle of the yield curve most heavily, with a peak effect at about two years, $\mathrm{QE}$ effects get larger as maturity increases, peaking at the 10-year maturity. Surprises about the current setting of monetary policy, which were present in the pre-ZLB period, never had noticeable effects on the long-end of the yield curve. Having the quantified QE surprises also allows us to study the persistence of their effects better. Unlike in the US, where QE effects were short lived, with a half-life of three months as estimated by Wright (2012), we estimate a half-life of about one year in the euro area. Thus, ECB QE not only had substantial immediate effects on yields, it also had long lasting effects.

We also study the effects of ECB policy surprises on different sovereign yields, exchange rates, and stock prices. Some of these were studied previously in the literature using the combined press release and press conference windows (such as Andrade and Ferroni, 2016) and in the separate windows but not including the QE surprises in the analysis (such as Brand et al., 2010 and Leombroni et al., 2017). This paper is the first to look at intraday data to separately study the press release and press conference windows and extract both conventional and unconventional monetary policy communication surprises from both. It is also the first not to assume only Target surprises take place in the press release and broadly defined "communication" surprises in the press conference windows but to ask statistically how many factors are present in each and to estimate factors that can be attributed to specific types of communication. Importantly, this paper is also the first in presenting a market-based identification of QE surprises in the euro area that shows QE has narrowed spreads, rather than identifying QE surprises by assuming that these have narrowed spreads.

In the limited cases where both the event window coverage and the monetary policy surprise definitions overlap with the existing literature, our findings are in line with what is already known-such as effects of Target surprises that are significant for the short end of the yield curve-and instills confidence for the new results we report on the difference between Timing and Forward Guidance, on the effects of $\mathrm{QE}$, on persistence of these effects, on information and stock market reactions,

1 Although the effective lower bound turned out to be below zero, we maintain the convention of calling the bound ZLB. 
on nonlinearity, and finally on using our methodology for the analysis of policy news that do not come out on Governing Council policy dates.

On stock prices, we find that the reaction of broad and banking indices can only be understood when the genuine policy surprises (perceived deviations of interest rates from the policy rule) are separated from information effects (perceived information signaled by the central bank on the current and future state). When studied using this lens, monetary policy has had significant effects on stock prices but there was significant time variance in the perceived variances of genuine policy and information surprises. We further find that the policy surprise effects on stocks were persistent as were the effects of these surprises on longer-term interest rates, especially for Forward Guidance and QE surprises.

Our findings on nonlinearity are noteworthy. We study whether the market responses to positive and negative surprises are different. A nascent literature is suggesting that in the US, monetary policy has asymmetric real effects (Barnichon and Matthes, 2017; Tenreyro and Thwaites, 2016). We find that in the euro area financial market participants do not perceive monetary policy effects to be asymmetric with respect to positive surprises and negative in providing asset price responses.

Lastly, we use our estimated factors of monetary policy surprises and show how to use them to decompose any policyrelated news effects into these four factors. In two illustrative examples we show that policymaker speeches and newswire reports can have substantial effects on yields and that in the recent past there have been cases where the financial market participants have extracted information on QE-related policy from such news.

The paper is organized as follows. In Section 2 below, we discuss the ECB policy communication and our event-study database. Then, in Section 3 we construct our surprises in terms of Target, Timing, Forward Guidance, and QE factors of monetary policy in the two policy communication windows, and discuss their features and plausibility. Section 4 presents asset price responses to the monetary policy surprises using a linear model. In Section 5 we turn to stock price reactions and information effects. In Section 6, we show how to adapt our methodology to speeches and other monetary policy events and in Section 7 present our main findings for persistence and non-linear effects, with the full analysis of those topics relegated to the Appendix. Lastly, in Section 8 we offer concluding thoughts.

\section{Euro area monetary policy event-study database}

One of the contributions of this paper is to develop a Euro Area Monetary Policy Event-Study Database (EA-MPD). ${ }^{2}$ This section is an introductory manual for the dataset, which will be periodically updated and made available. The underlying tick data come from the Thomson Reuters Tick History database, off of which we measure and report changes in asset prices over the relevant policy windows. Here, we first describe the monetary policy communication process in the euro area and then concentrate on the features of the dataset that we develop to measure the monetary policy surprises, delegating more technical details on the dataset construction to online appendices.

\subsection{A primer on euro area monetary policy communication}

At its inception in 1999, the ECB Governing Council took policy decisions twice a month, whereas a press conference took place only once a month, on the first meeting of the month. After November 2001 only one meeting per month was a policy meeting, taking place on the first Thursday of the month, regularly accompanied by the press conferences, with some exceptions (Ehrmann and Fratzscher 2009 discuss this policy communication structure). As of January 2015, the frequency of monetary policy meetings has moved to a six-week cycle. The online appendix (Appendix A) shows this information in summary form and in meeting-by-meeting detail. ${ }^{3}$

Part of our job in creating the EA-MPD was to compile this information in detail so that the intraday windows have the right coverage. On the day of a policy meeting, different from the US FOMC press release (and very helpfully for researchers), the ECB policy decision is announced in two separate steps. First, at 13.45 Central European Time (CET) a brief press release provides the policy decision without any explanation and rationale. Then, at 14.30 CET the ECB President reads a prepared text, the Introductory Statement (IS), on the rationale behind the decision, which market participants often perceive to be also informative about the future path of monetary policy. It takes about $15 \mathrm{~min}$ for the President to read out the statement and there is a follow up question-and-answer session with journalists that lasts for about 45 min. Up to December 2014 the press release referred to the decision on policy rates only, while announcements of non-standard measures were made in the

\footnotetext{
2 Details of the database construction are presented in Appendices B, C, and D. The database is updated periodically and is available at https://www.ecb. europa.eu/pub/pdf/annex/Dataset_EA-MPD.xlsx.

3 The Appendix is available online and is structured as follows: Appendix A provides details on the Governing Council meeting frequencies, the information release structure on policy dates and other relevant information since the inception of the ECB. It also contains a table that shows the policy rate decision and any other policy relevant announcements on each policy date. Appendix B describes our high-frequency dataset showing the Reuters Identification Code (RIC) and data availability, which varies by instrument under consideration. Appendix C explains the procedure we follow in cleaning the tick data. Appendix D describes the structure of the database and the main features of the instruments it covers. Appendix E shows the consistency checks we have performed on the computed asset price/yield changes. Appendix F describes the econometric procedure used in the paper to identify the market-based surprises. Appendix G compares the market-based surprise time series we built with market commentary for the largest surprises of each type. Appendix $\mathrm{H}$ contains the tables for the responses of Italian and Spanish sovereign yields, and the euro-dollar exchange rate to ECB policy surprises. Appendix I presents the details of our analysis of persistence of effects, and lastly Appendix J does the same for our analysis of possible non-linearity of asset price responses.
} 


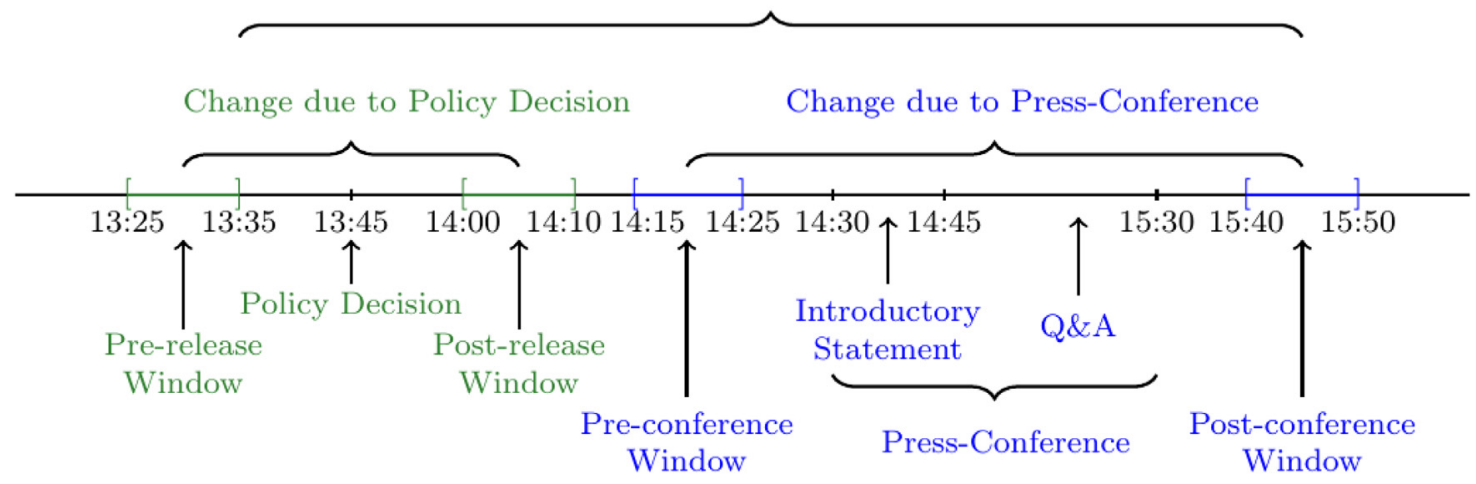

Fig. 1. ECB policy communication timeline.

Note: The figure shows the typical policy communication structure during a day of the Governing Council policy meeting of the ECB.

Introductory Statement during the press conference. Between January 2015 and January 2016 the press release mentioned whether "further measures" (without stating what measures were decided) will be announced during the press conference. As of March 2016, the content of the decisions on non-standard policy measures has been included in the press release.

In constructing the database, we first cleanse the data of misquotes, ${ }^{4}$ then discretize the data within each window by taking the last quote of each minute within the window, and then use the median price in the 13:25-13:35 interval as the pre-press-release quote, and the median price in the 14:00-14:10 as the post-press-release quote. Similarly, we take the median price in the 14:15-14:25 interval as the pre-conference quote and the median price in the 15:40-15:50 interval as the post-conference quote. We make use of an interval rather than selecting a particular minute to measure the pre- and post-event quotes in order to minimize the risk of selecting a quote that is not representative. The changes reported in the database are changes from the pre-event quote to the post-event quote for each communication window. We define the "monetary policy event" as the union of the press release and conference, and measure changes in asset prices due to this event as the change from the pre-press release quote to the post-conference quote. Fig. 1 shows this timeline in stylized form.

The EA-MPD reports the asset price/yield changes we construct for the three event windows in separate worksheets. In each worksheet a policy date is in the first column on each row, and the following columns show changes in selected asset prices/yields. The assets covered are: OIS rates with 1, 3, 6 month, 1 to 10, 15, and 20 year maturities; German bund yields with 3 and 6 month, 1 to 10, 15, 20, and 30 year maturities, French, Italian, and Spanish sovereign yields with 2, 5, and 10 year maturities, the STOXX50E and the stock price index comprising banks (SX7E), and the exchange rate of the euro. The EA-MPD is made available as a supplement to this paper and will be regularly updated.

In our substantive analysis we start the sample in 2002 because from 1999 (the beginning of the single currency in the Euro Area) to the end of 2001 our intraday OIS data are very noisy, with large spikes and sparse quotes. To provide an illustration of the (cleansed) intraday data, Fig. 2 shows the changes in the 2-year Overnight Index Swap (OIS) rate around the publication of the press release and around the press conference on four different policy meeting dates: 4 July 2013 , 4 September 2014, 3 December 2015, and 7 September 2017. We select the 2-year rate as it is of sufficiently long maturity to display movements in response to announcements of non-standard as well as standard measures.

These four panels are illustrative of the different cases in which the monetary policy surprises may arise within the policy meeting day. Panel (a) displays no reaction of the 2-year OIS rate in the press release window and a reaction in the conference window. This episode corresponds to the ECB announcement in the press conference, first time ever, of formal Forward Guidance on the future path of its policy rates, by stating that policy rates are expected to remain at present or lower levels for an extended period of time. Panel (b) shows a reaction in the press release window, with no further news affecting the OIS rate in the conference window. This episode corresponds to the announcement of a cut in the ECB deposit rate announced in the press release. Panel (c) depicts a policy date in which there are sizable movements in both windows. This episode captures the financial markets' disappointment following the ECB decision to increase the size of its QE program: markets evidently were expecting a larger increase of $\mathrm{QE}$, as well as a cut in the policy rate, as suggested also by survey expectations among financial analysts gathered ahead of the policy meeting. Lastly, panel (d) shows a day in which there is no surprise, either in the press release or the conference windows. Policy dates like these are surprisingly rare; there is usually some news for the financial markets, especially in the press conference window. While this discussion of the policy surprises on the basis of intraday changes in the 2-year OIS rate is suggestive of a Target/Path/QE decomposition, formally carrying out this analysis requires the simultaneous study of interest rates at different maturities, which are covered by our event-study database and analyzed in Section 3 below.

\footnotetext{
${ }^{4}$ Such misquotes, which did not reflect actual market pricing, were prevalent especially early in the sample.
} 

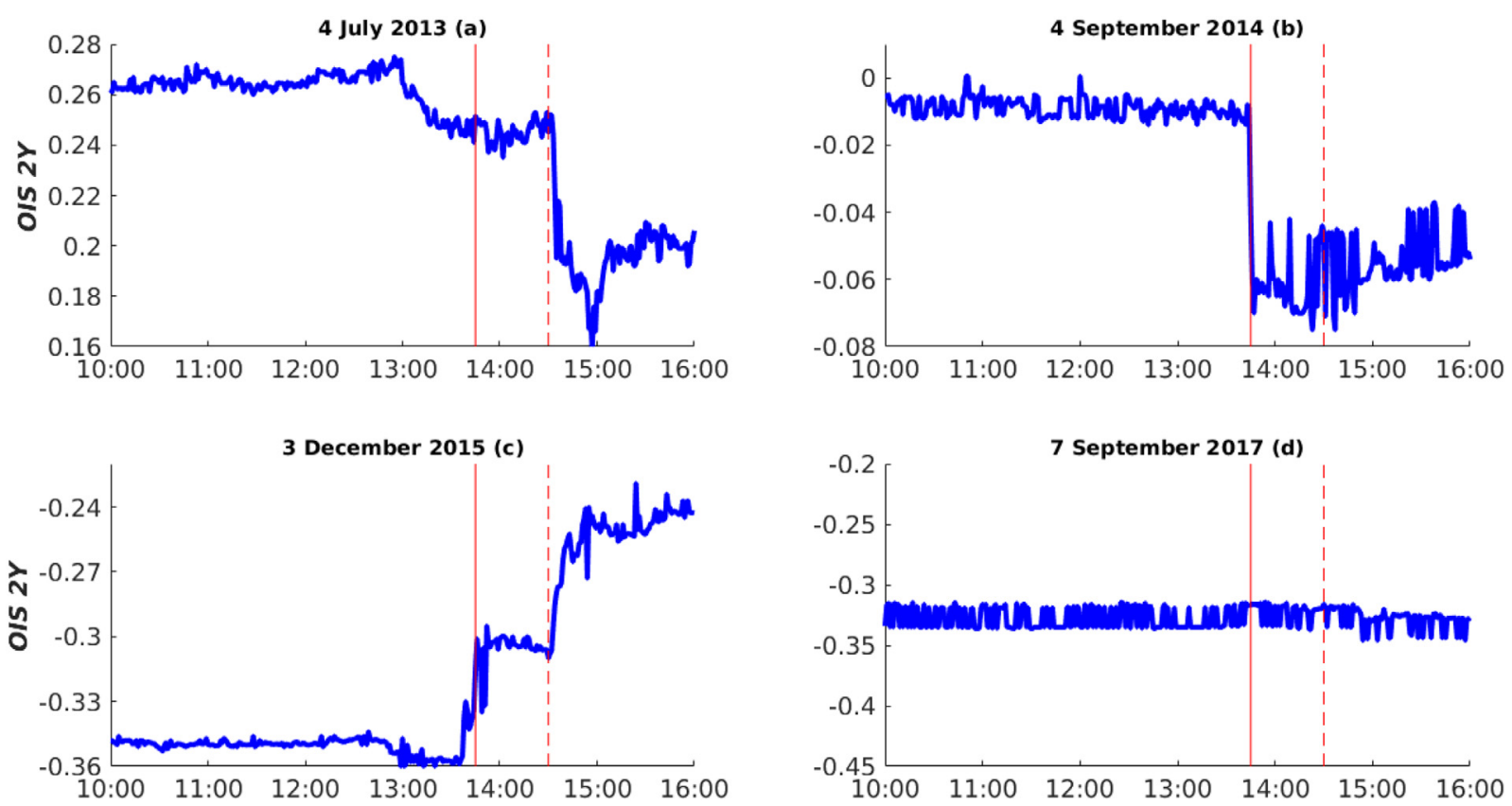

Fig. 2. Intraday 2-year OIS rate around the press release and the conference windows.

Note: The figure shows the intraday movement (percentage points on the $\mathrm{y}$-axis, trading hours on the $\mathrm{x}$-axis) in the 2-year OIS rate during four selected episodes. The vertical solid line marks the publication of the press release; the vertical dashed line marks the beginning of the press conference.

Before turning to the measurement of surprises it is useful to briefly note some of the internal consistency and robustness checks we have carried out on the data (Appendix E contains details and further checks). The raw changes and surprises we measure, and the results of the analysis we do using these are mostly insensitive to changes in the measurement windows. Our estimates would have been more or less the same if we had taken the last quote instead of the median within the window or used wider or narrower windows. We have also verified that the changes and surprises are independent across the two windows, showing that we are indeed measuring reactions to unanticipated news in the two windows and not momentum effects that carry over from one window to the other.

Another important issue has to do with the US data release calendar, which makes the initial unemployment claims release often overlap with the event windows in the Euro Area. In the window that contains both an ECB policy communication and the US initial claims release, ${ }^{5}$ although the two will be uncorrelated, if the short-term euro OIS rates respond to the initial claims surprise the monetary policy surprise measures will be subject to measurement error. We studied the impact of US initial claims surprises on short-term euro OIS rates and found that even in the very rare cases where there are statistically significant coefficients, the $R^{2}$ coefficients are in single digits, implying that the simultaneous release of US initial claims does not introduce noticeable measurement error into the Euro Area monetary policy surprises that we develop. For completeness we include these as control variables in the statistical work we present in Section 4 . It is reassuring that whether we include this control or not has no bearing on the results we report.

\section{Measuring policy surprises in the euro area}

Understanding the effects of monetary policy requires identifying orthogonal changes in the policy stance. These changes may be orthogonal to the state of the economy, as in VAR analysis-in which case they are usually called policy shocks-or they may be orthogonal to the information set of financial market participants-in which case they are called (market-based) policy surprises.

Using monetary policy surprises measured in daily or higher frequency one can study asset price responses to monetary policy in a meaningful way. The very reasonable identifying assumption here is that monetary policy does not respond to asset price changes within the day, hence causality goes from monetary policy to asset prices and financial markets' reaction to monetary policy can be studied. Work on related questions for the euro area have been done by Brand et al. (2010), Jardet and Monks (2014), Andrade and Ferroni (2016), Leombroni et al. (2017), Cieslak and Schrimpf (2018), Kane et al. (2018), Rogers et al. (2014), and Jarociński and Karadi (2018) among others. These papers collectively study the

\footnotetext{
${ }^{5}$ In the window that does not overlap with the initial claims release there is no correlation between the US surprise and the changes and surprises we measure for the Euro Area, again verifying that we are measuring proper surprises arising from monetary policy communication.
} 
financial and real effects of ECB policy measured using high frequency surprises, but do not do the decompositions of surprises as we do.

All of these papers had to construct their own event-study databases to carry out similar analyses. The EA-MPD we provide, by virtue of being regularly updated, will eliminate this sizable fixed cost of doing research on Euro Area monetary policy. In terms of the exercises we carry out, our value added will be in estimating rather than assuming the number of different types of policy surprises market participants perceive and in naming these. The results of this exercise are interesting and different from what has been assumed so far. Our further value added will be in covering the crisis period and measuring the effects of ECB non-standard monetary policy measures over a range of financial assets and comparing their transmission with that of standard policy measures, as well as measuring the persistence of responses and possible asymmetry of these responses to positive and negative surprises. In particular, we will be estimating the persistence of $\mathrm{QE}$ effects in the euro area using a precise, continuous measure of QE surprises for the first time.

\subsection{Identifying the surprises}

We first measure monetary policy as a potentially two dimensional process with possible Target/Timing and Path (Forward Guidance) components, and then allow for a third dimension after the onset of the financial crisis so as to capture the information about non-standard measures and especially QE. As noted above, the ECB policy communication extends over two separate windows where the policy action is first announced in a press release with no motivation, and then a statement is read by the President, followed by a question-and-answer session. Market participants may update their beliefs about the current stance and future path of monetary policy in response to the press release as well as the press conference; hence on each policy date, using intraday data, we measure two sets of surprises.

We construct the Target and Forward Guidance surprises following the methodology employed in Gürkaynak et al. (2005) and Gürkaynak (2005), who in turn build on the work of Kuttner (2001), using Federal Funds futures quotes to measure policy surprises in the US. The methodology of constructing the QE factor follows that of Swanson (2017). In particular, we extract factors from changes in yields of risk-free rates at different maturities, spanning one-month to ten-years, in each of the two windows (press release and conference). Ideally, the risk-free rate curve in the euro area would be proxied by the term structure of the OIS. Unfortunately, however, at maturities longer than 2 years high-frequency data on the OIS rates is only available after August 2011. Therefore, prior to that date we use yields on the German sovereign yields as proxy for the risk-free rates. Using the German yields throughout the period makes no significant difference.

To extract monetary policy surprises that admit economic interpretation from these asset price changes we estimate latent factors from changes in yields and rotate these factors. The matrix $X^{j}, j=$ \{press release, press conference $\}$, has changes in 1, 3, and 6-month and 1,2,5, and 10-year yields in its seven columns, with each row corresponding to a policy date. This matrix is taken directly from the EA-MPD. The factor structure is

$$
X^{j}=F^{j} \Lambda^{j}+\epsilon^{j},
$$

where $F$ are the common latent factors, $\Lambda$ are the factor loadings, and $\epsilon$ are the idiosyncratic variation of yields at different maturities. We analyze the press release and press conference windows separately and estimate the factors-common drivers of yield changes-by principal components.

We test the number of statistically significant factors in the two windows over the full sample and the pre-QE samples. As shown in Table 1, we consistently find a single significant factor in the press release window in both periods, but find

Table 1

Test of number of factors characterizing monetary policy announcements.

\begin{tabular}{lllll}
\hline & \multicolumn{2}{l}{ Press release window } & \multicolumn{2}{l}{ Conference window } \\
\hline & Pre-QE & Full sample & Pre-QE & Full sample \\
\hline$H_{0}: k=0$ & 46.20 & 49.12 & 105.50 & 108.49 \\
& $(0.001)$ & $(0.000)$ & $(0.000)$ & $(0.000)$ \\
$H_{0}: k=1$ & 18.77 & 22.55 & 33.73 & 39.42 \\
& $(0.174)$ & $(0.068)$ & $(0.002)$ & $(0.000)$ \\
$H_{0}: k=2$ & & & 14.87 & 17.44 \\
& & & $(0.062)$ & $(0.026)$ \\
$H_{0}: k=3$ & & & & 4.07 \\
& & & & $(0.254)$ \\
\hline
\end{tabular}

Note: The table reports the Wald statistics and associated p-values in parenthesis of Cragg and Donald (1997) test for testing the null hypothesis of $k=k_{0}$ factors against the alternative that $k>k_{0}$. The same test is performed on the two policy windows (press release and press conference) and for two different samples. The Pre-QE sample consists of all surprises due to monetary policy events taking places between January 2002 and December 2013. The full sample contains all the monetary surprises (January 2002-September 2018). 
two factors in the press conference window before $Q E$ and three in the full sample, suggesting the presence of a new factor in this window in the QE period. ${ }^{6}$

The latent factors $F^{j}$ do not have clean interpretations as monetary policy surprises, so we rotate the factors to make them interpretable. This method has been used frequently since Gürkaynak et al. (2005) and was first applied to Euro Area data by Brand et al. (2010) using intraday data. For our purposes, including the analysis of QE, the orthogonal factors are identified by imposing the following restrictions on the rotation matrix: (1) the second and third (when the third factor is present) factors do not load on the one-month OIS; (2) the rotation is such that the third factor has the smallest variance in the pre-crisis period (2 January 2002 - 7 Aug 2008). Essentially, we are forcing two factors not to be correlated with the one-month OIS (the standard measure of the immediate policy setting surprise) and allowing for one of them to affect the yield curve such that this factor was not important in the pre-crisis period. ${ }^{7}$ This factor will turn out to contribute only to the movements in the long-end of the yield curve, and only be active post-2014, naturally leading to the QE factor label. Extraction of this last factor is an application of the Swanson (2017) methodology to euro area monetary policy data. It is important to recognize that what matters for these surprises is how market participants interpret the policy news and how their expectations change following the policy news; our findings are not about the type of signal the central bank aims to provide.

The sequential nature of these orthogonalizations is important to keep in mind to understand the rotated factors. One factor is defined by orthogonality to the 1-month OIS change. Another is defined by orthogonality to this, such that the two explain most of the variance of the yields. The third factor is defined such that it is orthogonal to the first two and the 1-month OIS, and explains the minimal share of the pre-crisis variance. ${ }^{8}$

With these rotations, the first and only statistically significant factor in the press release window turns out to be the "Target" factor, which loads only on the short rates. As expected, we find a Forward Guidance (Path) factor that is always present in the press conference window. The existence of guidance by central banks predates the global financial crisis as well as the explicit designation of "Forward Guidance" and even the adoption of statements accompanying policy decisions. The Forward Guidance factor captures the revision in market expectations about the future path of policy rates that are orthogonal to the current policy surprise.

The other factor that is always present in the press conference window does not have factor loadings that lead to a Target interpretation. That factor does not load on the 1-month OIS much. This is mechanically possible because the rotation forces one factor to be orthogonal to 1-month OIS but does not force the other factor to closely follow it. The other factor in the press conference window turns out to be a "Timing" factor that captures the shifts in market expectations over the next few meetings that leaves longer-term interest rates essentially unchanged. It is therefore important to note that estimating a Target factor in the press release window and a Timing factor in the press conference window are findings, not assumptions. Similarly, the QE factor that loads only on longer-term yields is a finding interpretable this way, not ex-ante assumed.

The interpretable surprises we measure using the factor rotation are suitable for our research questions. Other decompositions of surprises are also possible and the EA-MPD will facilitate asking a variety of euro area monetary policy related questions. Some of the recent work in this vein are Jarociński and Karadi (2018), who use stock-bond correlations to identify central bank information signaling as opposed to classical monetary policy surprises; Andrade and Ferroni (2016), using index-linked swaps for the same purpose; and Cieslak and Schrimpf (2018), who use stocks and interest rates of short and long maturities to do a three-way decomposition between classical monetary policy surprises, information (on growth) surprises, and risk premium surprises.

We have also experimented with alternative identifying assumptions. Since we found a single factor in the press release window, identifying the Target factor by orthogonalizing with respect to a second factor may have been misleading so we used the change in the one-month OIS directly as the Target factor, which unsurprisingly made no difference. Similarly, not using the one-month OIS in the conference window (where it has negligible variance) and using orthogonality to threemonth OIS to do the factor rotation gave qualitatively the same results. Many other ways of identifying surprises are possible and will surely be used by other researchers.

\subsection{Policy surprises in the euro area}

Fig. 3 shows the loadings of the rotated factors over the seven maturities in the analysis. As the factors are identified up to scale, we scale them such that Target has unit effect on one-month OIS, Timing has unit effect on six-month OIS, Forward

\footnotetext{
${ }^{6}$ The full sample press conference window having three factors might also have been due to the two sub-samples having two factors each, but one of these being different across the pre- $\mathrm{QE}$ and $\mathrm{QE}$ periods. But the first two factors of the pre- $\mathrm{QE}$ and full samples are exactly the same, ruling out this interpretation. Further, although utilizing the test for only the QE sample is undesirable due to the very low degrees of freedom one would have, doing that nonetheless finds three factors in the press conference window in the QE period.

${ }^{7}$ Note that this would be a somewhat imperfect measure prior to November 2001, as over that period the Governing Council took policy decisions at a fortnightly frequency. (Note also that, as discussed above, although we make the event study entries for all dates available in the dataset, the analysis in this section and beyond uses data beginning in 2002.) In that case, the one-month OIS covers the next meeting as well, hence may capture changes in expectations about the next meeting in addition to the immediate policy surprise. There are very few, if any, quotes for the one-week OIS on many event dates. Otherwise utilizing that measure would have solved the problem of frequency of meetings being higher than the maturity of contract used for the period prior to November 2001.

${ }^{8} \mathrm{~A}$ more elaborate and formal presentation of the factor rotations is presented in Appendix F.
} 

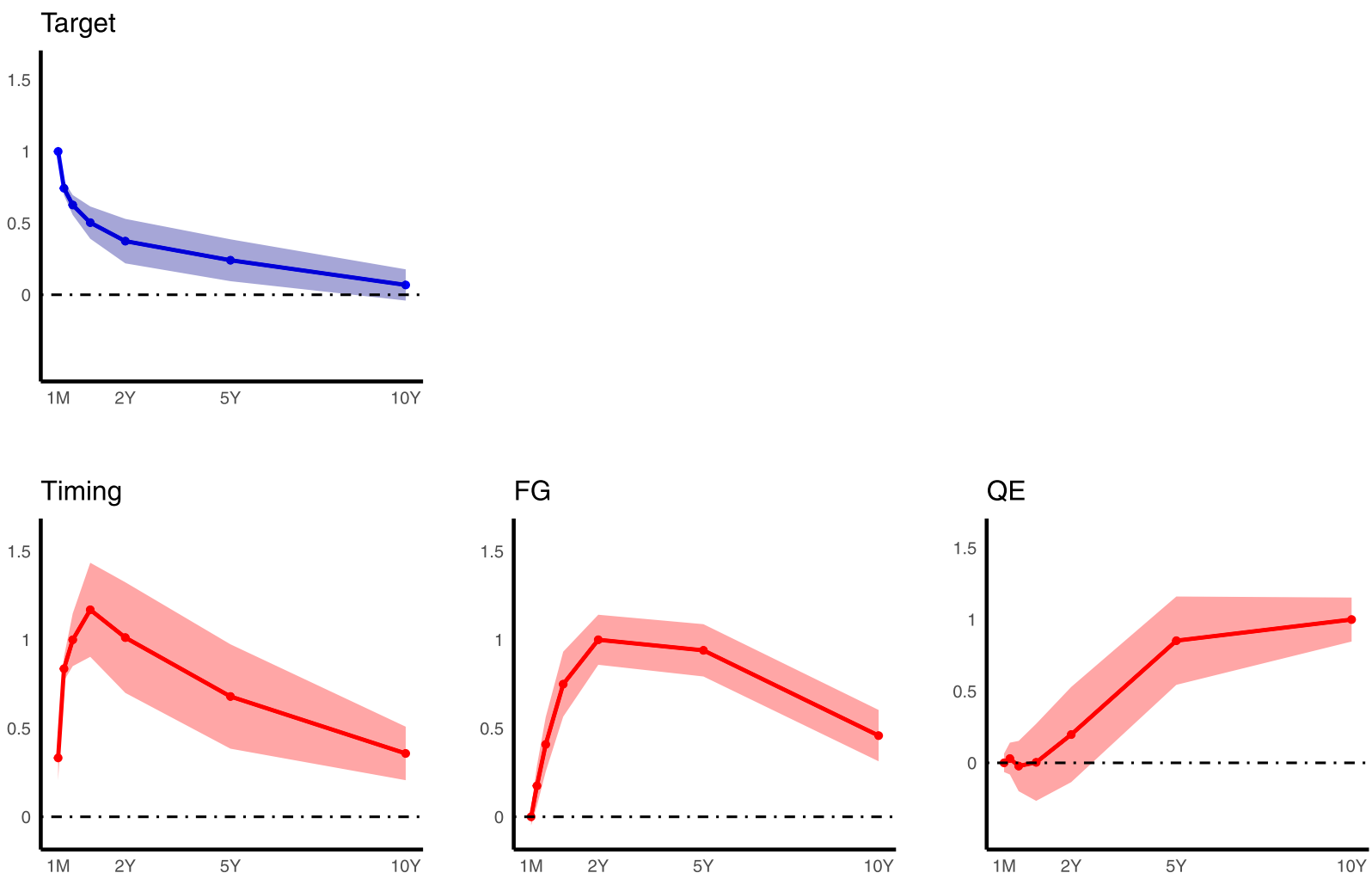

Fig. 3. Factor loadings.

Note: The figure shows the factor loadings for the press release (first row) and the conference windows (second row), in basis points. In each window, for each maturity the loadings are obtained by regressing the surprises onto the factors also controlling for the standardized surprise associated with the release of the US initial jobless claims. The Target and the Timing factors are normalized to have unit effect on the 1-month and 6-month OIS, respectively The Forward Guidance and QE factors are normalized to have unit effect on the 2-year and on the 10-year yields, respectively. The shaded areas indicate the $90 \%$ confidence intervals.

Guidance has unit effect on the two-year and QE has unit effect on the ten-year yields. This normalization has no effect on the variance shares and statistical significance of the results we report.

Note again that these factors are defined by the factor loadings, the shapes shown in Fig. 3 are not assumed but estimated. The assumptions we made are the orthogonality conditions discussed above. Our statistical tests tell us to look for a single factor in the press release window and three factors in the press conference window. (The third factor is only statistically present in the QE period but the factor loadings of all rotated factors are the same throughout the period. The $\mathrm{QE}$ factor has the same definition in the pre-QE period but is not contributing much to the overall variance, consistent with its label.) Those factors are rotated according to the orthogonality conditions assumed so that they may be interpretable. In the event, they turn out to have factor loadings shown in the figure and admit labels that have economic meaning. Notice in particular that the effect of $\mathrm{QE}$ was consistent with its design: the effect is greater the longer the maturity-recall that only the effect on the current-month OIS are set (to zero) by construction, whereas the effects on all other maturities are estimated. ${ }^{9}$

Table 2 shows the relative contribution (variance shares) of our identified factors in explaining changes across the riskfree rate curve in the press release and conference windows. This is a striking table showing that in the press release window yield curve variance is greatest in the shortest maturity to begin with, and the Target factor captures about all of the short-end volatility. Since there is no other statistically significant factor in this window and the Target factor does not load on the long-end at all, the volatility of the long-end is entirely in the idiosyncratic residual, but this volatility is small. Conversely, in the press conference window, the overall volatility is much higher and is concentrated on the longer-end of the yield curve, with a peak in volatility at two to five years, the maturities that are affected by both Forward Guidance and $\mathrm{QE}$. Thus, in the cases where much of the variance of a particular maturity is attributed to the residual, such as 10-years in the press release window or one-month in the press conference window, these have the lowest variances across the yield curve and the maturities with largest variances, one-month in the press release and two and five-years in the press conference windows are fully explained by the measured policy surprises.

\footnotetext{
${ }^{9} \mathrm{ECB}$ used a variety of maturities for its QE program, with an average maturity of about eight years. Hence, finding largest effects of QE on the long-end of the yield curve is as reasonable in the euro area as in the US.
} 
Table 2

Relative contribution of factors in explaining policy surprises, full sample.

\begin{tabular}{lllllllll}
\hline & 1-month & 3-month & 6-month & 1-year & 2-year & 5-year & 10-year & SD Factor \\
\hline $\begin{array}{l}\text { Press release } \\
\text { Target }\end{array}$ & 97.8 & 91.3 & 82.7 & 60.4 & 32.9 & 11.9 & 1.5 & 2.2 \\
Residual & 2.2 & 8.7 & 17.3 & 39.6 & 67.1 & 88.1 & 98.5 & NA \\
SD OIS rel. & 2.2 & 1.7 & 1.5 & 1.4 & 1.4 & 1.5 & 1.2 & $N A$ \\
Conference & & & & & & & \\
Timing & 54.8 & 86.7 & 70.3 & 50.0 & 29.6 & 14.7 & 9.5 & 2.3 \\
Forward Guidance & 0.0 & 9.1 & 28.1 & 49.0 & 68.9 & 67.3 & 37.2 & 3.6 \\
QE & 0.0 & 0.1 & 0.0 & 0.0 & 0.8 & 15.7 & 50.0 & 1.9 \\
Residual & 45.2 & 4.2 & 1.6 & 0.9 & 0.8 & 2.3 & 3.3 & NA \\
SD OIS conf. & 1.1 & 2.1 & 2.8 & 3.9 & 4.4 & 4.1 & 2.7 & NA \\
\hline
\end{tabular}

Note: The table reports, for the maturity of the OIS rates indicated in the first row, the fraction of the variance (in percentage points) explained by Target factor in the press release window and by each of the three factors (Timing, Forward Guidance, and $\mathrm{QE}$ ) in the conference window. The row labeled "Residual" reports the variance not explained by the factors. The last row in each panel shows the variance of the OIS rate at the relevant maturity measured in the release and conference windows respectively. The last column reports the standard deviations of the four factors.

As discussed above, we find that (a) changes of interest rates at short maturities in the press release window are mainly explained by the Target surprise, while in the conference window the Target surprise is absent and a "Timing" surprise emerges; (b) the Path (Forward Guidance) factor is present in the conference window and affects interest rates across all maturities above one month, with a typical hump-shaped pattern, and (c) the QE factor, present in the conference window, is differentiated from Forward Guidance by having an impact that is stronger the longer the maturity.

This finding is interesting and speaks to both the methodology of extracting the factors and the structure of monetary policy communication in the Euro Area. The methodology forces two of the factors, which we call Forward Guidance and QE factors, to be uncorrelated with the current interest rate surprise, in this case the change in the one-month OIS rate. The other factor is not forced to display the features of a Target factor (that is, not forced to be highly correlated with the change in the one month OIS rate) but in the press release window it turns out endogenously to be so, suggesting that Target is a dominant feature in the data. Recall that in the US policy window Target is always a dominant policy surprise as the policy decision and statement are simultaneously released; therefore this identification strategy in the US leads to finding the first factor to be Target.

In the euro area, in the conference window we find instead that the first factor does not look like a Target factor; it is not correlated with the one-month OIS at all. This has to be expected because once the current setting of policy is announced in the press release, updates to beliefs about Target should no longer be a dominant source of variation in the conference window. Indeed, principal components and the factor rotations that define Forward Guidance (Path) and QE lead to finding a remaining factor that does not display the features of a Target factor, but the features of a factor that resembles the Timing factor discussed by Gürkaynak et al. (2007). This is a factor that loads on the very near term (within six months) OIS rate changes and captures shifts in the perceived Timing of policy actions, such as beliefs that although a policy change did not happen today it is now more likely that it will happen in the next meeting or two. That is, the press conference makes the relative probabilities shift across very near-term meetings, as well as farther out. Forward Guidance captures changes in policy expectations affecting interest rates about two years out and Timing captures changes in expectations at a shorter horizon, affecting only to a small extent interest rates of longer maturities. Although we name these factors Timing and Forward Guidance, it is important to recognize that in essence these are two separate Forward Guidance factors, one with a peak effect at shorter maturities and the other at relatively longer maturities.

One can do the analysis with these factors, as we will, and keep in mind that the interpretations of factors across windows will be different: the first factor is Target in the press release window, and Timing in the conference window. Of course, it is possible to force the first factor to consistently be Target in both windows by imposing a large positive correlation of this factor with the change in the one-month OIS rate. In that case, the factor interpretations will be symmetric across windows, but this will come at the cost that less of the variance of the conference window will be explained: Timing, which we have shown is important, would have to turn into a residual. We continue with allowing for the Timing factor in the conference window.

As discussed in detail in Appendix G, the largest readings of the surprises correspond to well known dates and accord well with the market commentary. While we present the surprises and the statements that led to these in the appendix, a formal mapping between quantified words, as in Hansen and McMahon (2016), and the market perceptions we measure here has to be a separate paper.

\section{Asset price response to policy}

An important contribution of this paper is defining the interpretable policy surprise factors for the euro area. Once the policy surprises are measured as described in Section 3, causality is established, and the response of other asset prices can be studied via OLS. We estimate the impact of monetary policy on sovereign yields, the exchange rate, and the stock market. 
Table 3

Estimated effects of monetary policy surprises on OIS yields.

\begin{tabular}{|c|c|c|c|c|c|c|c|}
\hline \multicolumn{8}{|c|}{ Panel (A): Press release window } \\
\hline & $(1)$ & $(2)$ & (3) & $(4)$ & (5) & $(6)$ & (7) \\
\hline VARIABLES & OIS $1 \mathrm{M}$ & OIS $3 \mathrm{M}$ & OIS 6M & OIS $1 \mathrm{Y}$ & OIS $2 Y$ & OIS $5 Y$ & OIS $10 \mathrm{Y}$ \\
\hline Target & $\begin{array}{l}1.00^{* * *} \\
(0.02)\end{array}$ & $\begin{array}{l}0.74^{* * *} \\
(0.03)\end{array}$ & $\begin{array}{l}0.63^{* * *} \\
(0.04)\end{array}$ & $\begin{array}{l}0.50^{* * *} \\
(0.06)\end{array}$ & $\begin{array}{l}0.37^{* * *} \\
(0.08)\end{array}$ & $\begin{array}{l}0.24^{* * *} \\
(0.08)\end{array}$ & $\begin{array}{l}0.07 \\
(0.06)\end{array}$ \\
\hline Observations & 185 & 185 & 185 & 185 & 185 & 185 & 185 \\
\hline$R$-squared & 0.98 & 0.91 & 0.83 & 0.60 & 0.33 & 0.12 & 0.02 \\
\hline \multicolumn{8}{|c|}{ Panel (B): Conference window } \\
\hline & $(1)$ & (2) & (3) & $(4)$ & (5) & $(6)$ & (7) \\
\hline VARIABLES & OIS $1 \mathrm{M}$ & OIS $3 \mathrm{M}$ & OIS $6 \mathrm{M}$ & OIS $1 \mathrm{Y}$ & OIS $2 \mathrm{Y}$ & OIS $5 Y$ & OIS $10 \mathrm{Y}$ \\
\hline Timing & $\begin{array}{l}0.33^{* * *} \\
(0.07)\end{array}$ & $\begin{array}{l}0.84^{* * *} \\
(0.01)\end{array}$ & $\begin{array}{l}1.00^{* * *} \\
(0.02)\end{array}$ & $\begin{array}{l}1.17^{* * * *} \\
(0.02)\end{array}$ & $\begin{array}{l}1.01^{* * *} \\
(0.02)\end{array}$ & $\begin{array}{l}0.68^{* * *} \\
(0.03)\end{array}$ & $\begin{array}{l}0.36^{* * *} \\
(0.02)\end{array}$ \\
\hline FG & $\begin{array}{l}0.00 \\
(0.03)\end{array}$ & $\begin{array}{l}0.17^{* * *} \\
(0.01)\end{array}$ & $\begin{array}{l}0.41^{* * *} \\
(0.01)\end{array}$ & $\begin{array}{l}0.75^{* * *} \\
(0.01)\end{array}$ & $\begin{array}{l}1.00^{* * *} \\
(0.02)\end{array}$ & $\begin{array}{l}0.94^{* * *} \\
(0.03)\end{array}$ & $\begin{array}{l}0.46^{* * *} \\
(0.02)\end{array}$ \\
\hline QE & $\begin{array}{l}0.00 \\
(0.03)\end{array}$ & $\begin{array}{l}0.03 \\
(0.02)\end{array}$ & $\begin{array}{l}-0.02^{* *} \\
(0.01)\end{array}$ & $\begin{array}{l}0.00 \\
(0.02)\end{array}$ & $\begin{array}{l}0.20^{* * *} \\
(0.02)\end{array}$ & $\begin{array}{l}0.85^{* * * *} \\
(0.04)\end{array}$ & $\begin{array}{l}1.00 * * * \\
(0.03)\end{array}$ \\
\hline IJC & $\begin{array}{l}0.04 \\
(0.05)\end{array}$ & $\begin{array}{l}-0.04 \\
(0.03)\end{array}$ & $\begin{array}{l}0.02 \\
(0.03)\end{array}$ & $\begin{array}{l}0.00 \\
(0.03)\end{array}$ & $\begin{array}{l}-0.01 \\
(0.03)\end{array}$ & $\begin{array}{l}0.02 \\
(0.04)\end{array}$ & $\begin{array}{l}-0.01 \\
(0.03)\end{array}$ \\
\hline Observations & 180 & 180 & 180 & 180 & 180 & 180 & 180 \\
\hline$R$-squared & 0.55 & 0.96 & 0.98 & 0.99 & 0.99 & 0.98 & 0.97 \\
\hline
\end{tabular}

Note: The table reports the reaction of OIS and German sovereign yields at different maturities to surprises in monetary policy using intraday data. Coefficients are expressed in percentage per annum per standard deviation change in the factors. Robust standard errors in parentheses; ***,

${ }^{* *}$, and * denote statistical significance at the $1 \%, 5 \%$ and $10 \%$ levels, respectively.

In the conference window we continue to use the surprise in the US initial jobless claims as an additional control (labeled IJC) whenever we run regressions. Including or excluding the initial claims makes essentially no difference to our coefficients of interest.

Table 3 shows the intraday reaction of euro area risk-free rates to the Target surprise we have identified in the press release window (panel A) and the three surprises in the conference window (panel B). This table presents the information in Fig. 3 with numbers, the normalized factor loadings using an OLS regression framework and controlling for the US Initial Jobless Claims surprises in the press conference window. The loadings, which are essentially unchanged compared to Fig. 3 (the ECB policy surprises and US IJC surprises are not correlated) show the estimated weights over maturities in the full sample.

An interesting question is whether these factors have behaved the same way throughout the sample or whether the policy surprises elicited different responses before the crisis, during it before QE became a policy tool, and when QE was actively used. To study this, we run these regressions with samples up to 2008, 2008-2014, and 2014 to September 2018, corresponding to pre-crisis, crisis before $\mathrm{QE}$, and $\mathrm{QE}$ periods. The $\mathrm{QE}$ factor is of course only active in the last period.

Tables 4-6 show the results. Here, remember that these factors are defined as before (loadings do not change across tables) and are normalized such that Target, Timing, Forward Guidance, and QE factors have unit effects on one-month, six-month, two-year and 10-year yields in the full sample. Hence, the coefficients are comparable across tables and strongly show that these surprises functioned almost exactly the same way throughout our sample. Once the ZLB was binding there were fewer Target surprises but to the extent they took place, their effects were confined to the short end, with a rapid decay. Timing always has an early hump with little effect on the shortest and longest maturities. Forward guidance always affects intermediate maturities the most and $\mathrm{QE}$, when present, affects the long-end only. Importantly, these statements are true quantitatively as well, the coefficients differ little across subsamples, and fits, as measured by $R^{2}$ are also similar, showing that the relevance of the factors have not changed in terms of aggregate variance explained.

Notice that this analysis is only possible with our factor estimation methodology. While assuming that a "communication" surprise is present in the press conference window may be appropriate for some purposes, that approach would find a changing response to the communication surprise over time because OIS rate changes in this window would be capturing different types of information; dominantly Forward Guidance before 2014 and dominantly QE afterwards. That is, the surprise, not the response would be changing. Our methodology tracks different types of surprises, keeping their definitions the same across sub-samples, and shows that reactions to these have not changed markedly over time.

Having verified the consistency of our surprise measures across subsamples for the euro area risk-free rates, we now turn to their their effects on the sovereign yields of Italy and Spain. ${ }^{10}$ The results, shown in detail in Appendix $\mathrm{H}$, document that these factors affected the sovereign yields the same way they affected the safe rates. Importantly, QE, when active, has

\footnotetext{
${ }^{10}$ Effects on German rates are indistinguishable from effects on OIS rates when both are available and effects on French rates very closely follow German ones. We do not separately report or discuss these.
} 
Table 4

Estimated effects of monetary policy surprises on OIS, 01/2002-12/2007.

\begin{tabular}{|c|c|c|c|c|c|c|c|}
\hline \multicolumn{8}{|c|}{ Panel (A): Press release window } \\
\hline & (1) & (2) & (3) & (4) & (5) & (6) & (7) \\
\hline VARIABLES & OIS $1 \mathrm{M}$ & OIS $3 \mathrm{M}$ & OIS $6 \mathrm{M}$ & OIS $1 Y$ & OIS $2 \mathrm{Y}$ & OIS $5 \mathrm{Y}$ & OIS $10 \mathrm{Y}$ \\
\hline Target & $\begin{array}{l}1.03^{* * *} \\
(0.02)\end{array}$ & $\begin{array}{l}0.62^{* * *} \\
(0.03)\end{array}$ & $\begin{array}{l}0.42^{* * *} \\
(0.03)\end{array}$ & $\begin{array}{l}0.22^{* * *} \\
(0.06)\end{array}$ & $\begin{array}{l}0.01 \\
(0.09)\end{array}$ & $\begin{array}{l}-0.04 \\
(0.11)\end{array}$ & $\begin{array}{l}-0.07 \\
(0.10)\end{array}$ \\
\hline Observations & 72 & 72 & 72 & 72 & 72 & 72 & 72 \\
\hline$R$-squared & 0.98 & 0.85 & 0.69 & 0.22 & 0.00 & 0.01 & 0.03 \\
\hline \multicolumn{8}{|c|}{ Panel (B): Conference window } \\
\hline & (1) & (2) & (3) & (4) & (5) & (6) & (7) \\
\hline VARIABLES & OIS $1 \mathrm{M}$ & OIS $3 \mathrm{M}$ & OIS $6 \mathrm{M}$ & OIS $1 Y$ & OIS $2 \mathrm{Y}$ & OIS $5 \mathrm{Y}$ & OIS $10 \mathrm{Y}$ \\
\hline Timing & $\begin{array}{l}0.23 * * * \\
(0.07)\end{array}$ & $\begin{array}{l}0.87^{* * *} \\
(0.05)\end{array}$ & $\begin{array}{l}0.98^{* * *} \\
(0.04)\end{array}$ & $\begin{array}{l}1.18^{* * *} \\
(0.04)\end{array}$ & $\begin{array}{l}1.07^{* * *} \\
(0.04)\end{array}$ & $\begin{array}{l}0.57^{* * *} \\
(0.14)\end{array}$ & $\begin{array}{l}0.44^{* * *} \\
(0.07)\end{array}$ \\
\hline FG & $\begin{array}{l}0.02 \\
(0.03)\end{array}$ & $\begin{array}{l}0.15^{* * *} \\
(0.03)\end{array}$ & $\begin{array}{l}0.42^{* * *} \\
(0.01)\end{array}$ & $\begin{array}{l}0.78^{* * *} \\
(0.02)\end{array}$ & $\begin{array}{l}0.99^{* * *} \\
(0.05)\end{array}$ & $\begin{array}{l}1.14^{* * * *} \\
(0.13)\end{array}$ & $\begin{array}{l}0.63^{* * *} \\
(0.06)\end{array}$ \\
\hline $\mathrm{IJC}$ & $\begin{array}{l}-0.03 \\
(0.06)\end{array}$ & $\begin{array}{l}-0.05 \\
(0.04)\end{array}$ & $\begin{array}{l}0.10^{* *} \\
(0.05)\end{array}$ & $\begin{array}{l}0.00 \\
(0.03)\end{array}$ & $\begin{array}{l}-0.11^{* * *} \\
(0.04)\end{array}$ & $\begin{array}{l}-0.02 \\
(0.12)\end{array}$ & $\begin{array}{l}-0.17^{*} \\
(0.09)\end{array}$ \\
\hline Observations & 67 & 67 & 67 & 67 & 67 & 67 & 67 \\
\hline$R$-squared & 0.34 & 0.92 & 0.97 & 0.99 & 0.98 & 0.88 & 0.78 \\
\hline
\end{tabular}

Note: The table reports the reaction of OIS and German sovereign yields at different maturities to surprises in monetary policy using intraday data. Coefficients are expressed in percentage per annum per standard deviation change in the factors. Robust standard errors in parentheses; ${ }^{* * *}$, ${ }^{* *}$, and ${ }^{*}$ denote statistical significance at the $1 \%, 5 \%$ and $10 \%$ levels, respectively.

Table 5

Estimated effects of monetary policy surprises on OIS, 01/2008-12/2013.

\begin{tabular}{|c|c|c|c|c|c|c|c|}
\hline \multicolumn{8}{|c|}{ Panel (A): Press release window } \\
\hline & (1) & $(2)$ & (3) & (4) & (5) & (6) & (7) \\
\hline VARIABLES & OIS $1 \mathrm{M}$ & OIS $3 \mathrm{M}$ & OIS 6M & OIS $1 Y$ & OIS $2 Y$ & OIS $5 Y$ & OIS $10 \mathrm{Y}$ \\
\hline Target & $\begin{array}{l}1.00^{* * * *} \\
(0.03)\end{array}$ & $\begin{array}{l}0.77^{* * * *} \\
(0.03)\end{array}$ & $\begin{array}{l}0.67^{* * *} \\
(0.02)\end{array}$ & $\begin{array}{l}0.58^{* * *} \\
(0.04)\end{array}$ & $\begin{array}{l}0.47^{* * *} \\
(0.06)\end{array}$ & $\begin{array}{l}0.31^{* * *} \\
(0.09)\end{array}$ & $\begin{array}{l}0.10 \\
(0.08)\end{array}$ \\
\hline Observations & 71 & 71 & 71 & 71 & 71 & 71 & 71 \\
\hline$R$-squared & 0.98 & 0.97 & 0.95 & 0.79 & 0.53 & 0.20 & 0.04 \\
\hline \multicolumn{8}{|c|}{ Panel (B): Conference window } \\
\hline & (1) & $(2)$ & (3) & (4) & $(5)$ & (6) & (7) \\
\hline VARIABLES & OIS $1 \mathrm{M}$ & OIS $3 \mathrm{M}$ & OIS 6M & OIS 1Y & OIS $2 Y$ & OIS $5 Y$ & OIS $10 \mathrm{Y}$ \\
\hline Timing & $\begin{array}{l}0.34^{* * *} \\
(0.08)\end{array}$ & $\begin{array}{l}0.81^{* * *} \\
(0.02)\end{array}$ & $\begin{array}{l}1.02^{* * *} \\
(0.02)\end{array}$ & $\begin{array}{l}1.18^{* * *} \\
(0.03)\end{array}$ & $\begin{array}{l}0.98^{* * *} \\
(0.03)\end{array}$ & $\begin{array}{l}0.62^{* * *} \\
(0.04)\end{array}$ & $\begin{array}{l}0.27^{* * *} \\
(0.06)\end{array}$ \\
\hline FG & $\begin{array}{l}0.02 \\
(0.03)\end{array}$ & $\begin{array}{l}0.18^{* * *} \\
(0.01)\end{array}$ & $\begin{array}{l}0.39 * * * \\
(0.01)\end{array}$ & $\begin{array}{l}0.73^{* * *} \\
(0.01)\end{array}$ & $\begin{array}{l}1.01^{* * *} \\
(0.01)\end{array}$ & $\begin{array}{l}0.87^{* * *} \\
(0.04)\end{array}$ & $\begin{array}{l}0.38^{* * *} \\
(0.06)\end{array}$ \\
\hline IJC & $\begin{array}{l}0.21^{* *} \\
(0.09)\end{array}$ & $\begin{array}{l}-0.05 \\
(0.05)\end{array}$ & $\begin{array}{l}-0.07^{* *} \\
(0.04)\end{array}$ & $\begin{array}{l}-0.00 \\
(0.05)\end{array}$ & $\begin{array}{l}0.01 \\
(0.05)\end{array}$ & $\begin{array}{l}-0.27 \\
(0.27)\end{array}$ & $\begin{array}{l}-0.28 \\
(0.27)\end{array}$ \\
\hline Observations & 71 & 71 & 71 & 71 & 71 & 71 & 71 \\
\hline$R$-squared & 0.64 & 0.98 & 0.99 & 0.99 & 0.99 & 0.86 & 0.51 \\
\hline
\end{tabular}

Note: The table reports the reaction of OIS and German sovereign yields at different maturities to surprises in monetary policy using intraday data. Coefficients are expressed in percentage per annum per standard deviation change in the factors. Robust standard errors in parentheses; ***, **, and * denote statistical significance at the $1 \%, 5 \%$ and $10 \%$ levels, respectively.

affected Spanish and especially Italian long-term yields more than the safe rate, narrowing spreads on impact, consistent with the evidence in Altavilla et al. (2015).

As judged by the high $R^{2} \mathrm{~S}$ of the regressions, the monetary policy surprises we extracted capture large fractions of yield changes for risk-free and sovereign rates, especially in the conference window for the last subsample for long rates, as the QE factor helps explain the 10-year yield changes. In the earlier samples the $R^{2}$ for long rates are lower but the variance of these rates are also lower without QE surprises that move them. This is in contrast to Leombroni et al. (2017), who find that spreads were widened due to Forward Guidance surprises in a study that did not separately assess QE effects. We therefore find that the first stage of monetary policy transmission is not different across the largest euro area countries. The real effects may be different due to non-financial differences across them, as argued by Corsetti et al. (2018) but that is a separate topic of study. 
Table 6

Estimated effects of monetary policy surprises on OIS, 01/2014-09/2018.

\begin{tabular}{|c|c|c|c|c|c|c|c|}
\hline \multicolumn{8}{|c|}{ Panel (A): Press release window } \\
\hline & (1) & (2) & (3) & (4) & (5) & (6) & (7) \\
\hline VARIABLES & OIS $1 \mathrm{M}$ & OIS $3 \mathrm{M}$ & OIS $6 \mathrm{M}$ & OIS $1 Y$ & OIS $2 Y$ & OIS $5 Y$ & OIS $10 \mathrm{Y}$ \\
\hline Target & $\begin{array}{l}0.88^{* * *} \\
(0.08)\end{array}$ & $\begin{array}{l}1.05^{* * *} \\
(0.12)\end{array}$ & $\begin{array}{l}1.11^{* * *} \\
(0.18)\end{array}$ & $\begin{array}{l}1.04^{* * *} \\
(0.14)\end{array}$ & $\begin{array}{l}1.09^{* * *} \\
(0.17)\end{array}$ & $\begin{array}{l}0.92^{* * *} \\
(0.18)\end{array}$ & $\begin{array}{l}0.45^{*} \\
(0.25)\end{array}$ \\
\hline Observations & 42 & 42 & 42 & 42 & 42 & 42 & 42 \\
\hline$R$-squared & 0.91 & 0.85 & 0.80 & 0.79 & 0.65 & 0.43 & 0.11 \\
\hline \multicolumn{8}{|c|}{ Panel (B): Conference window } \\
\hline & (1) & (2) & (3) & (4) & (5) & (6) & (7) \\
\hline VARIABLES & OIS $1 \mathrm{M}$ & OIS $3 \mathrm{M}$ & OIS 6M & OIS 1Y & OIS $2 Y$ & OIS $5 Y$ & OIS $10 \mathrm{Y}$ \\
\hline Timing & $\begin{array}{l}0.58^{* * *} \\
(0.13)\end{array}$ & $\begin{array}{l}0.91 * * * \\
(0.07)\end{array}$ & $\begin{array}{l}0.92^{* * *} \\
(0.04)\end{array}$ & $\begin{array}{l}1.03^{* * *} \\
(0.05)\end{array}$ & $\begin{array}{l}1.06^{* * *} \\
(0.04)\end{array}$ & $\begin{array}{l}0.83^{* * *} \\
(0.10)\end{array}$ & $\begin{array}{l}0.21^{* * *} \\
(0.08)\end{array}$ \\
\hline FG & $\begin{array}{l}-0.05 \\
(0.08)\end{array}$ & $\begin{array}{l}0.14^{* *} \\
(0.05)\end{array}$ & $\begin{array}{l}0.48^{* * *} \\
(0.02)\end{array}$ & $\begin{array}{l}0.74^{* * *} \\
(0.03)\end{array}$ & $\begin{array}{l}1.00^{* * *} \\
(0.02)\end{array}$ & $\begin{array}{l}0.91^{* * *} \\
(0.05)\end{array}$ & $\begin{array}{l}0.49^{* * *} \\
(0.04)\end{array}$ \\
\hline $\mathrm{QE}$ & $\begin{array}{l}-0.06^{*} \\
(0.03)\end{array}$ & $\begin{array}{l}-0.04 \\
(0.03)\end{array}$ & $\begin{array}{l}-0.00 \\
(0.02)\end{array}$ & $\begin{array}{l}0.09^{* * *} \\
(0.03)\end{array}$ & $\begin{array}{l}0.21^{* * *} \\
(0.02)\end{array}$ & $\begin{array}{l}0.73^{* * *} \\
(0.06)\end{array}$ & $\begin{array}{l}1.10^{* * *} \\
(0.05)\end{array}$ \\
\hline IJC & $\begin{array}{l}-0.04 \\
(0.10)\end{array}$ & $\begin{array}{r}-0.02 \\
(0.11)\end{array}$ & $\begin{array}{l}0.04 \\
(0.07)\end{array}$ & $\begin{array}{l}0.03 \\
(0.04)\end{array}$ & $\begin{array}{l}-0.06^{*} \\
(0.03)\end{array}$ & $\begin{array}{l}0.04 \\
(0.06)\end{array}$ & $\begin{array}{l}-0.02 \\
(0.05)\end{array}$ \\
\hline Observations & 42 & 42 & 42 & 42 & 42 & 42 & 42 \\
\hline$R$-squared & 0.71 & 0.87 & 0.95 & 0.96 & 0.99 & 0.97 & 0.99 \\
\hline
\end{tabular}

Note: The table reports the reaction of OIS rates at different maturities to surprises in monetary policy using intraday data. Coefficients are expressed in percentage per annum per standard deviation change in the factors. Robust standard errors in parentheses; ${ }^{* * *},{ }^{* *}$, and ${ }^{*}$ denote statistical significance at the $1 \%, 5 \%$ and $10 \%$ levels, respectively.

\subsection{Exchange rate}

In exchange rates, where we again relegate the reporting of the detailed results to Appendix $\mathrm{H}$, we find that the surprises exert a statistically significant effect on the exchange value of the euro. The $R$-squared of the regression for the conference window is about 0.6 , which is very large for work involving exchange rates on the left-hand-side.

It is also noteworthy that in our samples the Rogers et al. (2014) "preserving the euro effect" where easing surprises make the euro appreciate, does not manifest itself. This effect, while certainly present on some days, is dominated by the standard uncovered interest parity channel in the periods of our analysis.

These findings are broadly consistent with the work of Faust et al. (2007), who show that "good news" in data releases in the US lead to an appreciation of the dollar and relate this to uncovered interest parity. We find that higher rates than anticipated in the euro area similarly lead to an appreciation of the euro, as expected. There is not much of a literature on whether current rates or expected future interest rates, or short versus long-term interest rates theoretically should be and empirically are the main drivers of exchange rates. Our empirical findings suggest that changing interest rate expectations at all maturities as a result of monetary policy communication affect the exchange value of the euro.

\section{Stock prices and the information surprise}

Table 7 shows the intraday reaction of the euro area stock market to the Target surprise (panel A) and the three surprises in the conference window (panel B). The response is statistically significant and negative (surprises that increase yields lead to stock index declines) for the Target factor in the full sample and the pre-crisis sample, and for the Timing and Forward Guidance factors in the post-2014 sample. Results for the stock market index comprising only euro area banks are similar.

Lack of significance for some of the factors in some sub-samples may be expected in light of the recent literature arguing that any monetary policy decision (or no decision) may be interpreted by markets in two different ways: a textbook monetary policy shock or a perceived revelation of information about the state of the economy. This latter type of policy is called Delphic in Campbell et al. (2012) and information shock in Miranda-Agrippino and Ricco (2018) and Jarociński and Karadi (2018). For our analysis, it is important to note that the responses of nominal rates to the two types of surprises are qualitatively similar. A positive policy surprise increases yields if it is a genuine shock, but perceived information that the state of the business cycle is stronger than thought also similarly increases yields by increasing future expected short rates. Therefore, possible information effects do not interfere with our identification strategy of the factors.

However, the two types of surprises have opposite effects on stocks. Lower rates are good news (lower discount rates and higher demand) but learning that the cyclical state is worse than previously thought is bad news (lower dividends). One can see similar effects on inflation expectations; a positive policy surprise should decrease inflation compensation implied by indexed securities unless the surprise is perceived to be signalling information about high inflationary pressures, in which case inflation compensation will increase. The macroeconomic impacts of these policy surprises are also found to 
Table 7

Estimated effects of monetary policy surprises on stock prices.

\begin{tabular}{|c|c|c|c|c|c|c|c|c|}
\hline \multicolumn{9}{|c|}{ Panel (A): Press release window } \\
\hline & (1) & $(2)$ & (3) & (4) & (5) & (6) & $(7)$ & $(8)$ \\
\hline VARIABLES & STOXX50E & STOXX50E & STOXX50E & STOXX50E & SX7E & SX7E & SX7E & SX7E \\
\hline Target & $\begin{array}{l}-0.04^{* * *} \\
(0.02)\end{array}$ & $\begin{array}{l}-0.08^{* * *} \\
(0.02)\end{array}$ & $\begin{array}{l}-0.03 \\
(0.02)\end{array}$ & $\begin{array}{l}-0.07 \\
(0.14)\end{array}$ & $\begin{array}{l}-0.03 \\
(0.02)\end{array}$ & $\begin{array}{l}-0.07^{* * *} \\
(0.01)\end{array}$ & $\begin{array}{l}-0.03 \\
(0.02)\end{array}$ & $\begin{array}{l}0.14 \\
(0.24)\end{array}$ \\
\hline Observations & 185 & 72 & 71 & 42 & 185 & 72 & 71 & 42 \\
\hline$R$-squared & 0.08 & 0.36 & 0.06 & 0.03 & 0.01 & 0.46 & 0.03 & 0.03 \\
\hline \multicolumn{9}{|c|}{ Panel (B): Conference window } \\
\hline & (1) & $(2)$ & (3) & (4) & $(5)$ & (6) & $(7)$ & $(8)$ \\
\hline VARIABLES & STOXX50E & STOXX50E & STOXX50E & STOXX50E & SX7E & SX7E & SX7E & SX7E \\
\hline Timing & $\begin{array}{l}-0.00 \\
(0.02)\end{array}$ & $\begin{array}{l}-0.01 \\
(0.03)\end{array}$ & $\begin{array}{l}0.02 \\
(0.02)\end{array}$ & $\begin{array}{l}-0.24^{*} \\
(0.12)\end{array}$ & $\begin{array}{l}0.00 \\
(0.03)\end{array}$ & $\begin{array}{l}-0.00 \\
(0.03)\end{array}$ & $\begin{array}{l}0.02 \\
(0.03)\end{array}$ & $\begin{array}{l}-0.30^{* *} \\
(0.11)\end{array}$ \\
\hline FG & $\begin{array}{l}-0.02 \\
(0.02)\end{array}$ & $\begin{array}{l}0.01 \\
(0.02)\end{array}$ & $\begin{array}{l}-0.03 \\
(0.02)\end{array}$ & $\begin{array}{l}-0.23^{* *} \\
(0.09)\end{array}$ & $\begin{array}{l}-0.04^{*} \\
(0.02)\end{array}$ & $\begin{array}{l}-0.00 \\
(0.02)\end{array}$ & $\begin{array}{l}-0.05 \\
(0.03)\end{array}$ & $\begin{array}{l}-0.25^{\text {*** }} \\
(0.08)\end{array}$ \\
\hline $\mathrm{QE}$ & $\begin{array}{l}-0.01 \\
(0.04)\end{array}$ & & & $\begin{array}{l}-0.07 \\
(0.04)\end{array}$ & $\begin{array}{l}0.07 \\
(0.08)\end{array}$ & & & $\begin{array}{l}0.02 \\
(0.07)\end{array}$ \\
\hline $\mathrm{IJC}$ & $\begin{array}{l}-0.07^{*} \\
(0.04)\end{array}$ & $\begin{array}{l}-0.11^{* *} \\
(0.05)\end{array}$ & $\begin{array}{l}-0.04 \\
(0.06)\end{array}$ & $\begin{array}{l}-0.05 \\
(0.10)\end{array}$ & $\begin{array}{l}-0.06 \\
(0.06)\end{array}$ & $\begin{array}{l}-0.12^{* * *} \\
(0.04)\end{array}$ & $\begin{array}{l}-0.06 \\
(0.10)\end{array}$ & $\begin{array}{l}-0.03 \\
(0.14)\end{array}$ \\
\hline Observations & 180 & 67 & 71 & 42 & 180 & 67 & 71 & 42 \\
\hline$R$-squared & 0.03 & 0.12 & 0.05 & 0.35 & 0.04 & 0.10 & 0.03 & 0.17 \\
\hline
\end{tabular}

Note: The table reports the reaction of the general euro area stock market index over different samples (columns 1 to 4 ), and the reaction of the euro area bank stock market sub-index over the same samples (columns 5 to 8 ) to surprises in monetary policy using intraday data. Coefficients are expressed in percentage points per standard deviation change in the factors. Robust standard errors in parentheses; ${ }^{* * *}{ }^{* *}$, and ${ }^{*}$ denote statistical significance at the $1 \%, 5 \%$ and $10 \% 1$ levels, respectively.

differ depending on whether the policy surprise triggers a positive or negative response of the stock market (Jarociński and Karadi, 2018) or, similarly, a positive or negative response of inflation-linked swaps (Andrade and Ferroni, 2016), as measured at high-frequency around policy events. ${ }^{11}$ Therefore, the presence of these two types of policy can make the response of the stock market, on average, insignificant and can produce the results reported in Table 7.

To assess whether there is evidence of these two types of surprises in our dataset, for each policy event we compare the sign of the response of the stock market and inflation-linked swaps. If nominal rates, stock prices and inflation-linked swaps all move in the same direction, this would suggest that information shocks may be prevailing. To overcome the problem that data on inflation compensation are not reliably available at intraday frequency, we adapt our analysis to daily frequency and measure the interest rate reaction as the fitted value of the one-day change (around the policy events) of the 2-year OIS regressed on the intraday factors. We do the same for the one-day change of inflation-linked swaps and the one-day log-difference of stock prices.

Fig. 4 shows the dates for which stock prices and inflation swaps move in the same direction so that the market perception of policy can be clearly interpreted as information (Delphic) or pure policy (Odyssean) surprises. ${ }^{12}$ The figure shows that there is a marked difference across sub-samples in terms of the information market participants extract from policy surprises. Whereas in the post-2014 sub-sample (bottom panel) information shocks (defined as nominal interest rates, stock prices, and inflation-linked swaps moving in the same direction) are rare, these are frequent during the crisis sub-sample (top panel). That is, in the crisis period market participants attributed more of the surprises they perceived to information they thought the ECB has, consistent with a similar finding for the US by Lunsford (2018).

To delve deeper into this issue we build a daily VAR. The identification strategy is based on the idea of using highfrequency monetary policy surprises to isolate the variation in the reduced-form residuals in the VAR due to monetary policy shocks. The use of external instruments for identification in macroeconometric models goes back to Stock and Watson (2012) and Mertens and Ravn (2013). We start the analysis by estimating the reduced form VAR as described in Eq. (2).

$$
Y_{t}=c+\sum_{j=1}^{p} B_{j} Y_{t-j}+A_{0} u_{t}
$$

\footnotetext{
11 Jarociński and Karadi (2018) use intraday data employing stocks whereas Andrade and Ferroni (2016) use daily data due to lack of reliable intraday data for inflation-linked swaps.

12 In about $80 \%$ of the policy dates stock prices and inflation-linked swaps move in the same direction. In the other $20 \%$, in almost all of the cases the stock price reaction is about zero and the inflation-linked swap reaction is very small. Hence, these two measures almost never meaningfully disagree. Therefore, incidentally, our results verify Andrade and Ferroni (2016) and Jarociński and Karadi (2018) methods against each other and find that they are in agreement.
} 


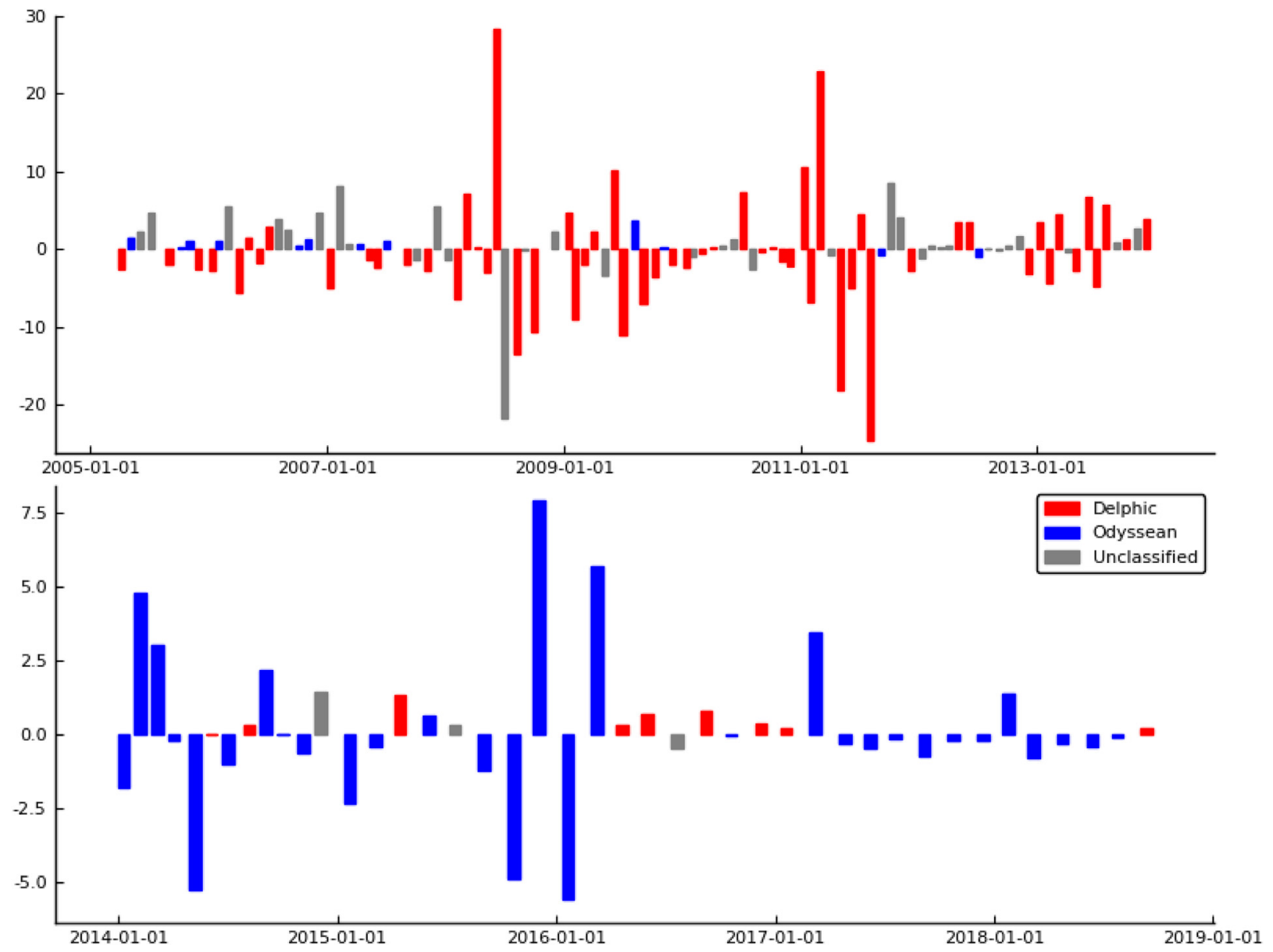

Fig. 4. Information and monetary policy surprises around GC meetings.

Note: The figure shows the changes in 2-year OIS on ECB Governing Council Policy Meeting Dates in the pre- and post-QE periods in the first and second panel respectively. Days in which the 2-year OIS, log STOXX50E, and 2-year Inflation-linked swap variables comove (red bars) have predominantly information surprises (Delphic), while days in which bond yields move in the opposite direction of the other two (blue bars) have predominantly pure monetary policy surprises (Odyssean). Grey bars represent the other cases (Unclassified). (For interpretation of the references to colour in this figure legend, the reader is referred to the web version of this article.)

where $Y_{t}$ is a vector consisting of the 2-year OIS, the log EUR-USD exchange rate, the log of the stock market index (Euro Stoxx 50), and the 2-year inflation linked swap (ILS2Y). As we are only interested in the effects of monetary policy shocks, our objective is to identify the column of the matrix $A_{0}$ corresponding to the contemporaneous effect of the monetary policy shock.

The instrument must satisfy the relevance and exogeneity assumptions:

$$
E\left(Z_{t} u_{t}^{m}\right)=\alpha \neq 0, \quad E\left(Z_{t} u_{t}^{o}\right)=0,
$$

where $Z_{t}$ is the instrument, and $u_{t}^{m}$ and $u_{t}^{o}$ denote the monetary and the non-monetary shocks. Our instruments will be the policy surprises we have identified. The external instruments are Target (press release), the Timing, the Forward Guidance, and the QE factor (press conference) factors. As the VAR residual is a linear combination of structural shocks, we instrument the residuals of the VAR with one instrument at a time, as we aim to extrapolate the component correlated with the Target, Timing, Forward Guidance and Quantitative Easing surprises respectively. As a different exercise, one can also include all the instruments simultaneously, however, this will only help to identify a single monetary policy shock which reflects a linear combination of the four. To be consistent with the previous analysis, we use the intraday factors as external instruments for the VAR estimated on all sub-samples. When analyzing Quantitative Easing, the instrument is used on the period 2014-2018.

Fig. 5 shows that in the post-2014 sub-sample each factor exerts a significant impact, with a decline in interest rates triggering a rise in stock prices and inflation-linked swaps, and a depreciation of the euro. In the 2008-2013 sub-sample the impact of each factor is significant, but we find that this time a decline in interest rates triggers a decline in stock prices and inflation linked-swaps, consistent with a perceived revelation of negative news. The exchange rate is found to depreciate, suggesting that it does not react differently, at least qualitatively, to an information shock. In the pre-crisis sub- 
Target
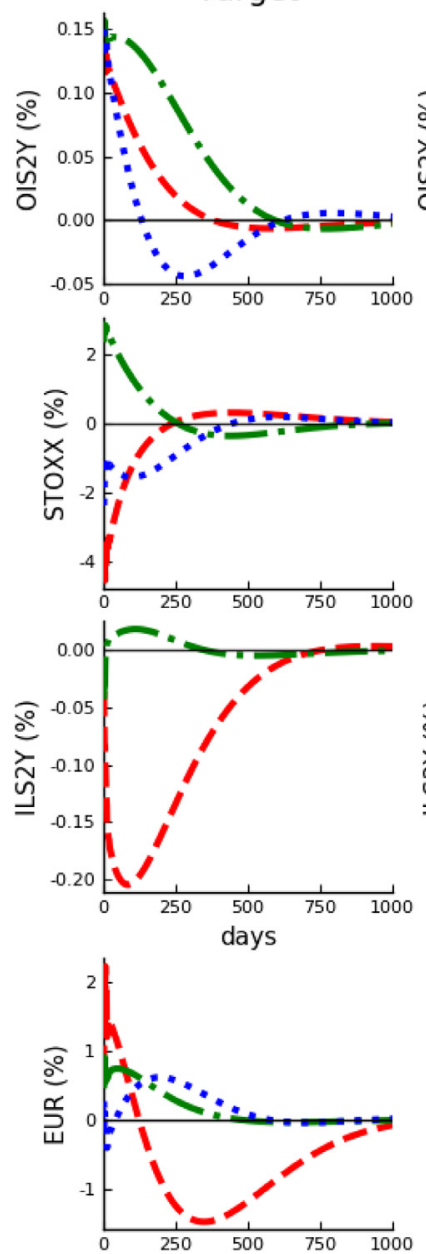

Timing
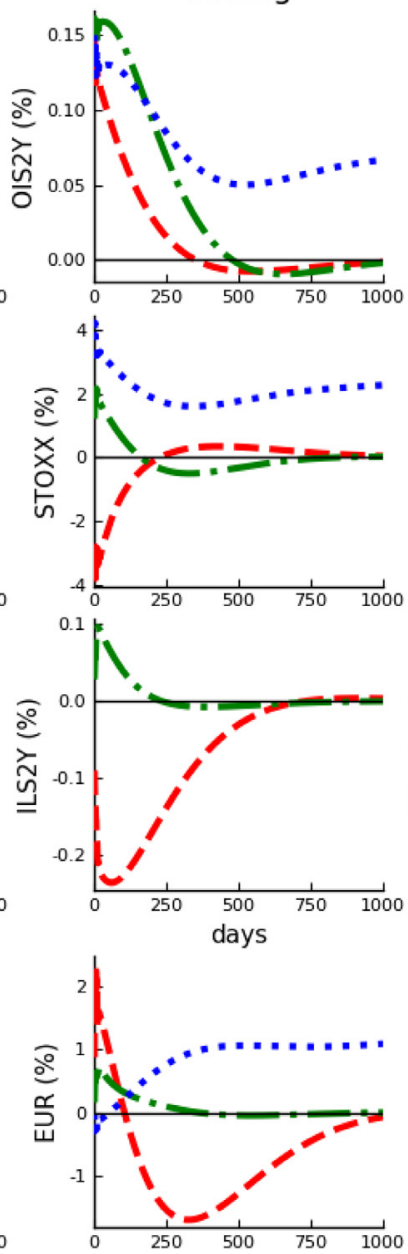

FG
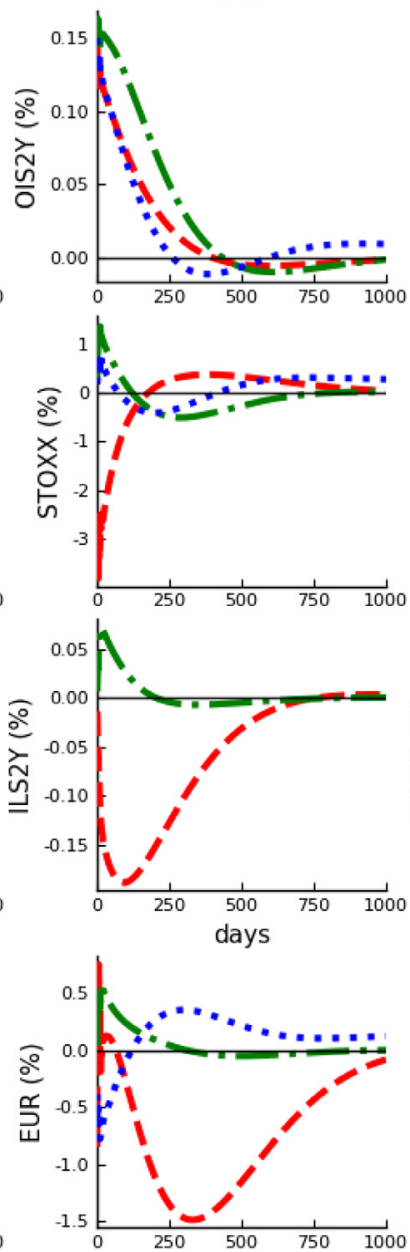

$\mathrm{QE}$
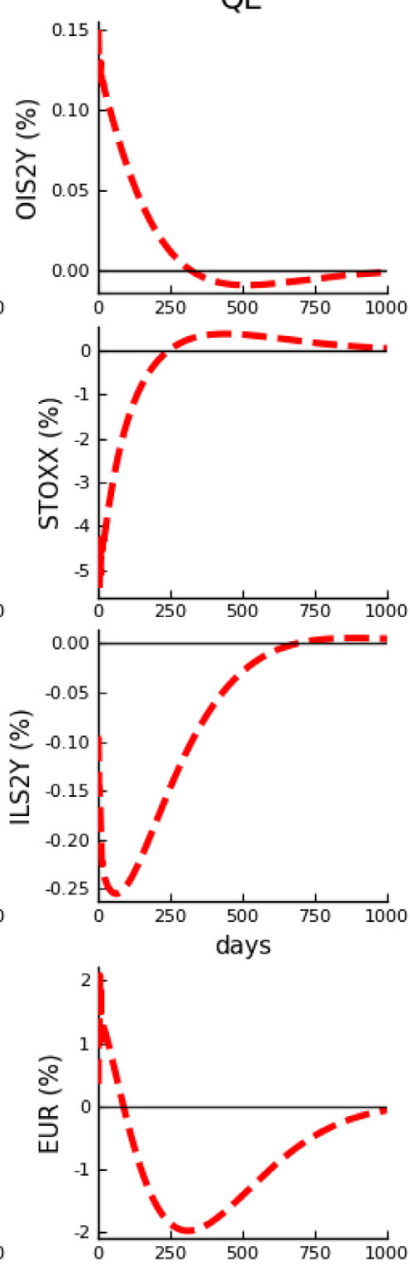

Fig. 5. Financial VAR.

Note: The figures show the IRFs of a financial 4-variable VAR, including 2Y OIS, log STOXX50E, ILS2Y and the log EUR/USD exchange rate. Blue-dotted lines show the IRFs for the pre-crisis period (2005-2008), green-dash-dotted lines for the pre-QE period (2008-2014), and the red-dashed lines, for the QE period (2014-2018). The $\mathrm{x}$-axis units are days. (For interpretation of the references to colour in this figure legend, the reader is referred to the web version of this article.)

sample of 2002-2007 we find that stock prices go down in response to positive Target surprise while there is no clear pattern for Timing and Forward Guidance surprises. Over that sub-sample we cannot use inflation-linked swaps as they become available only in 2005 .

Overall, these results suggest that there is evidence of information shocks and that stock prices and inflation-linked swaps may both help in telling apart these shocks from the more traditional policy shocks. We find that these results are fairly persistent, they do not only manifest themselves on policy dates then disappear. The results also suggest that it is possible to extend and generalise the macroeconomic analysis of Andrade and Ferroni (2016) and Jarociński and Karadi (2018). They use the overall policy surprise as measured by the high-frequency change of the 2-year OIS around policy events. Our analysis shows that it is possible to compute the macroeconomic response to each of the factors we have identified including $Q E$. The important finding of this section is that ECB policy surprises do have effects on stock prices but to properly study these one needs to separate traditional surprises from perceived information revelation, as we have briefly shown here. We do not go into a discussion of whether perceived "information" is about the current or future state, or about the reaction function of the central bank, although this is an important topic for future research.

\section{Decomposing various policy news}

Policy events that are not covered by our data set-policy communications that are not Governing Council policy decisions-can also be analyzed using our methodology. Policymaker speeches, releases of minutes and the like are also policy communication and have financial market effects. We can treat these events as if they are Governing Council policy 

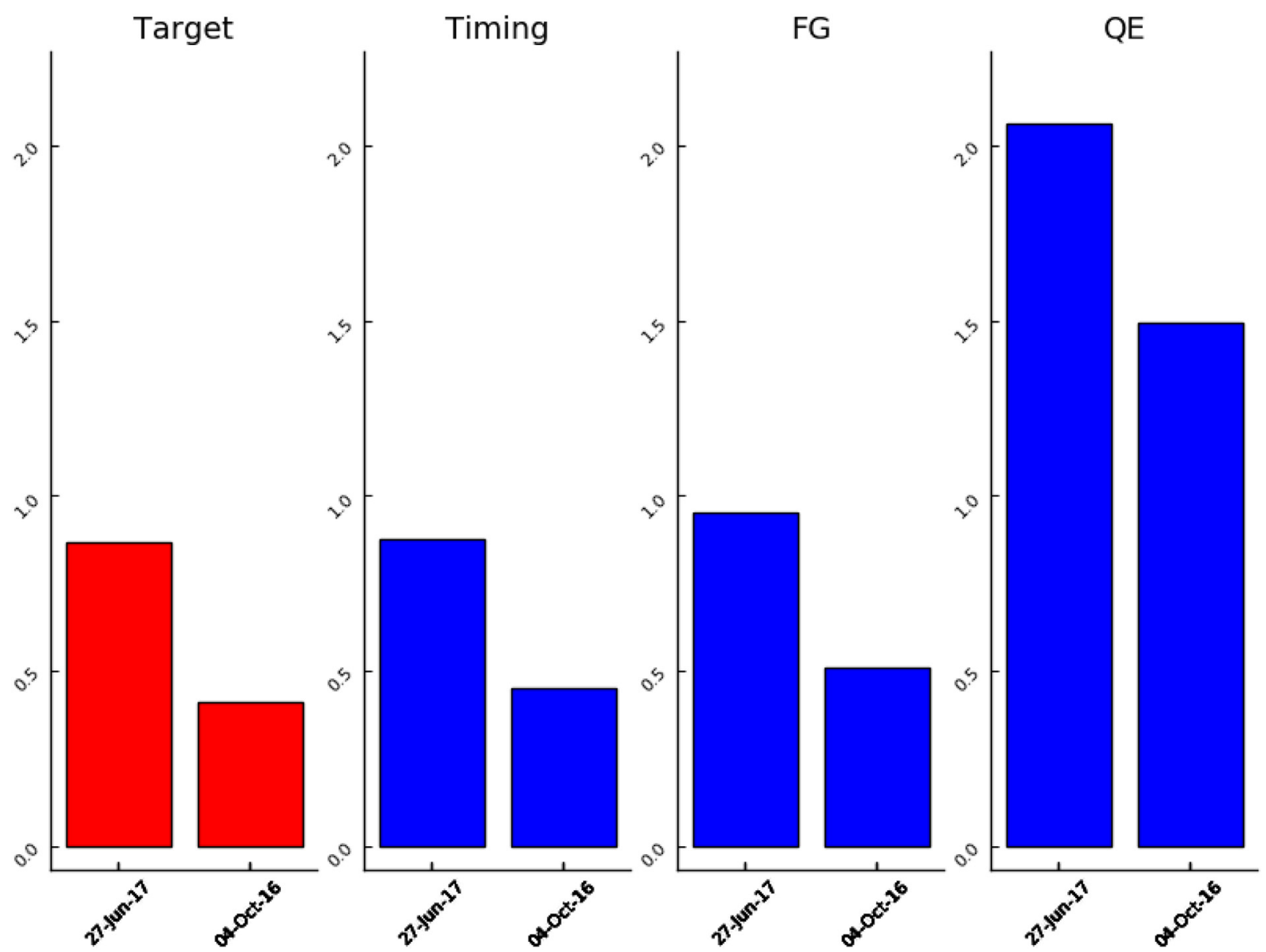

Fig. 6. Estimated factors for the two events.

Note: The figures show the estimated factor decomposition into Target, Timing, FG and QE factors of the two monetary policy events not included in our sample. In each subplot the first bar is for the June 2017 Draghi speech and the second one is for the October 2016 Bloomberg news article.

dates and, given the factor loadings we estimated for our factors, use the changes in the OIS yields in those event windows to decompose the market perception into Target, Timing, Forward Guidance, and QE surprises. This is an exercise in finding the combination of monetary policy surprise factors that best fit the change in yields around the relevant window.

The methodology is straightforward; for a particular event $i$-e.g., a speech-we take a window long enough to bracket the beginning and the end of the event, and compute the change in the $1 \mathrm{M}, 3 \mathrm{M}, 6 \mathrm{M}, 1 \mathrm{Y}, 2 \mathrm{Y}, 5 \mathrm{Y}$, and $10 \mathrm{Y}$ OIS. We collect these yield changes in a vector $O I S_{i}$, and, given the (rotated) factor loadings $\hat{\Lambda}$ we estimated from the EA-MPD, we find the factors $\hat{F}_{i}$ which minimize the sum of squared residuals of $\left(O I S_{i}-F_{i} \hat{\Lambda}\right)$. That is

$$
\hat{F}_{i}=\underset{F_{i}}{\arg \min }\left(O I S_{i}-F_{i} \hat{\Lambda}\right)^{\prime}\left(O I S_{i}-F_{i} \hat{\Lambda}\right)
$$

The solution of this minimization problem can be recognized as the OLS estimator of $F_{i}$, in a regression of OIS $S_{i}$ onto the space spanned by $\hat{\Lambda}$.

We apply our methodology to two illustrative events that elicited noticeable market reactions. The first is a speech given by Mario Draghi on 27 June 2017 at the ECB Forum on Central Banking in Sintra "Accompanying the economic recovery". The second is a Bloomberg news article by Jana Randow, Alessandro Speciale, and Jeff Black which was released on October 4, 2016 and hinted at a decision on tapering by the ECB. ${ }^{13}$

Fig. 6 shows our estimated factors for these two events, in terms of the Target, Timing, FG, and QE decomposition. To make the factors comparable to what were shown earlier in this paper, we rescale them as in Section 3, and we report them

\footnotetext{
${ }^{13}$ Since we are interested in the market perception, we do not go into the details of the events but provide Bloomberg headlines for each event to give context. On the 2017 speech: "Draghi Sees Room for Paring Stimulus Without Tightening Policy", "ECB president says forces damping inflation are temporary". On the 2016 news report: "Informal consensus among ECB policymakers is that QE will need to be wound down gradually when decision is taken to end the program, say people familiar with the matter", "One scenario is to taper QE in steps of EU10b/month, people say".
} 
as a fraction of the average absolute value of the in-sample surprise of each type. Note, as before, that the different scalings imply that magnitudes are comparable across different dates for the same type of surprise, but not across different types of surprises.

As expected, our exercise finds a large QE factor in both events. For the first event, we found a relatively large Forward Guidance component as well. "Large" here is with respect to the in-sample average size of these surprises. The normalization we used imply that a reading of any factor above unity means that factor was larger than its average absolute reading insample.

A few notes on this exercise are in order. First of all, we show that it is possible to map our understanding of identified policy surprises based on the analysis of Governing Council policy announcements into any other kind of policy news. This is of independent interest. Secondly, the Target factor is also estimated here. One can of course treat these news as analogous to press conferences and limit the possible factors to Timing, Forward Guidance, and QE but to the extent that market participants update their beliefs about outcomes of policy meetings within a month, one may measure a reaction interpretable as Target.

Lastly, this is a good place to discuss methodological choices. Our methodology is based only on the changes in safe rates of different maturities: the factors, including $\mathrm{QE}$, do not load on individual country yields or spreads. Thus, the QE surprise we identify is one that lowers the long-term euro area safe rate and we can show, as a finding, that this QE surprise also lowers spreads. One should think of this as a "macroeconomic easing QE." An alternative is QE that is perceived to particularly affect the Italian and Spanish yields, as in Rogers et al. (2014). Measuring this requires having spreads in the matrix from which one extracts the factors; we chose not to follow this path. For example, as spreads narrowed sharply around the "whatever it takes" speech, this second type of QE factor would have signaled a very large QE easing surprise by definition. ${ }^{14}$

Using our methodology, we are able to show that the macroeconomic easing QE factor that we identify also narrows spreads but we are silent about QE that may be perceived to differentially affect sovereign yields rather than providing overall stimulus. Clearly it is possible to measure a second type of QE and indeed to measure the two simultaneously, by allowing for two different types of QE surprises. Our research questions are best answered by the rotated factors we identified, but work on speeches of the "whatever it takes" type, or on the particular experiences of periphery countries may require alternative surprise identifications and associated factor rotations.

\section{Extensions: persistence and non-linearity}

Two other issues that we study in depth but relegate to the appendix to keep the paper of reasonable length are the persistence and possible non-linearity of responses. Here we briefly note the main findings for these topics.

On persistence (Appendix I), we find that the effects are notably persistent, especially for Forward Guidance and QE. Using a daily VAR with many combinations of variables we show that, very robustly, QE affected safe rates and sovereign yields at the 10-year maturity for a long duration, with a half-life of about one year. This is much longer than the about three month half-life Wright (2012) and Swanson (2017) find for the US, although we caution that methodological differences do not allow direct comparisons.

On non-linearity (Appendix J), our results are notable for the lack of asymmetry they imply. Market reactions have been remarkably symmetric with respect to positive and negative surprises. In particular, we find no evidence that easing surprises elicit a smaller market reaction than tightening ones in contrast to the nascent literature (for the US) that monetary policy easings may have smaller effects on the real economy (Barnichon and Matthes, 2017; Tenreyro and Thwaites, 2016).

\section{Conclusions}

Our aims in writing this paper were twofold. First, we wanted to explain and make available what we expect to be the standard euro area monetary policy event-study database, the EA-MPD. The paper discusses the construction of this data set. This is data we carefully analyzed and cleaned so that misquotes that were prevalent in the early period of ECB policymaking do not lead to spurious findings. The data will be continuously updated and made available online. Our second aim was to show the use of this data in constructing euro area monetary policy surprises, to decompose these into surprises in policy action, policy path, and QE news.

The two-stage nature of ECB policy news dissemination turns out to be very helpful in both increasing the number of data points and making statistical analysis more precise, and also in providing a validity check for our surprise measures. Comfortingly, we find that the Target surprises were dominant in the announcement window but that in the conference window this factor does not even exist, with news about future path of policy the main driver of yield changes before QE, and that QE news were present in the latter part of our sample, only in the conference window. These all dovetail with

\footnotetext{
14 The "Whatever it takes" speech by Mario Draghi is perhaps the most famous of euro area policy communications. We do not use it as an example here because we do not have data on the intraday five-year OIS yield for that event. However, the minor increase in the 10-year OIS yield around that speech suggests that our methodology would have interpreted this event, if anything, as a small QE tightening surprise. Identifying QE surprises by utilizing spreads would not lead to this finding for this speech but in that case QE would narrow spreads by assumption, and we would not be able to discuss effects of $\mathrm{QE}$ on spreads.
} 
the general understanding of how the ECB policy communication is designed to operate. We show that in practice policy communication has indeed worked as designed. We studied the response of various asset prices to these surprises and learned that surprises in the immediate setting of monetary policy, Target surprises, have effects only on the short end of the yield curve while Timing, Forward Guidance, and QE surprises all affect longer-term yields but in different ways.

It is important to emphasize again that rather than assuming the presence of predefined surprises in different windows, we estimated and identified these, finding a multifaceted information structure in the press conference window. We further learned that sovereign yields and exchange rates respond to ECB policy communication in interpretable ways, based on the source of the surprise. Importantly, QE turns out to have lowered all yields and narrowed spreads. Also importantly, we show that this effect was long-lived, with a half life of about a year. This is much longer than what was found earlier in the literature, when QE surprises were not quantified, and effects were based only on the dates of QE announcements.

Among other extensions, we showed that measuring the information surprise in ECB policy employing stock prices or inflation compensation yield similar results and this decomposition is needed to understand stock price reactions to monetary policy. We also showed how to use the identified policy surprise factors to analyze any policy communication, not only Governing Council policy releases and statements on meeting dates.

We hope that the event-study dataset that we have compiled and will regularly update will foster more research on monetary policy and its effects in the euro area. Questions about the effects of monetary policy on markets in different countries, how these differ by the fundamentals of those countries, using the surprises to help identify VAR-based real effects in the Gertler and Karadi (2015) fashion, and the transmission of ECB policies to non-euro area countries are some of the questions that continue to be important for academics and policymakers alike. While we shed more light than before on measuring and assessing monetary policy in the euro area, there certainly is much to be done.

\section{Supplementary material}

Supplementary material associated with this article can be found, in the online version, at doi:10.1016/j.jmoneco.2019. 08.016.

\section{References}

Altavilla, C., Carboni, G., Motto, R., 2015. Asset purchase programmes and financial markets: lessons from the euro area. ECB Working Paper, No. 1864.

Andrade, P., Ferroni, F., 2016. Delphic and odyssean monetary policy shocks: evidence from the euro-area. Discussion Papers in Economics, University of Surrey.

Barnichon, R., Matthes, C., 2017. Functional approximations of impulse responses (FAIR): new insights into the asymmetric effects of monetary policy. Manuscript, Federal Reserve Bank of San Francisco.

Brand, C., Buncic, D., Turunen, J., 2010. The impact of the ECB monetary policy decisions and communication on the yield curve. J. Eur. Econ. Assoc. 8 (6), 1266-1298. doi:10.1111/j.1542-4774.2010.tb00555.x.

Campbell, J.R., Evans, C.L., Fisher, J.D., Justiniano, A., 2012. Macroeconomic effects of federal reserve forward guidance. Brookings Pap. Econ. Act. 2012 (1), $1-80$.

Cieslak, A., Schrimpf, A., 2018. Non-Monetary News in Central Bank Communication. mimeo.

Corsetti, G., Duarte, J.B., Mann, S., 2018. One Money, Many Markets - A Factor Model Approach to Monetary Policy in the Euro Area with High-Frequency Identification. mimeo.

Ehrmann, M., Fratzscher, M., 2009. Explaining monetary policy in press conferences. Int. J. Cent. Bank. 5 (2), $42-84$

Faust, J., Rogers, J.H., Wang, S.-Y. B., Wright, J.H., 2007. The high-frequency response of exchange rates and interest rates to macroeconomic announcements. J. Monetary Econ. 54 (4), 1051-1068

Gertler, M., Karadi, P., 2015. Monetary policy surprises credit costs, and economic activity. Am. Econ. J.1 7 (1), 44-76. doi:10.1257/mac.20130329.

Gürkaynak, R., 2005. Using federal funds futures for monetary policy analysis. FEDS Working Paper 2005-29.

Gürkaynak, R.S., Sack, B., Swanson, E.T., 2005. Do actions speak louder than words? The response of asset prices to monetary policy actions and statements. Int. J. Cent. Bank. 1 (1), 55-93.

Gürkaynak, R.S., Sack, B., Swanson, E.T., 2007. Market-based measures of monetary policy expectations. J. Bus. Econ. Stat. 25 (2), $201-212$.

Hansen, S., McMahon, M., 2016. Shocking language: understanding the macroeconomic effects of central bank communication. J. Int. Econ. 99 (S1), S114-S133.

Jardet, C., Monks, A., 2014. Euro area monetary policy shocks: impact on financial asset prices during the crisis?. Document de Travail 512.

Jarociński, M., Karadi, P., 2018. Deconstructing monetary policy surprises: the role of information shocks. ECB Working Paper, 2133.

Kane, A., Roger, J., Sun, B., 2018. Communications Breakdown: The Transmission of Different Types of ECB Policy Announcements. mimeo.

Kuttner, K.N., 2001. Monetary policy surprises and interest rates: Evidence from the Fed funds futures market. J. Monetary Econ. 47 (3), 523-544. doi:10. 1016/s0304-3932(01)00055-1.

Leombroni, M., Vedolin, A., Venter, G., Whelan, P., 2017. Central Bank Communication and the Yield Curve. mimeo.

Lunsford, K., 2018. Understanding the aspects of federal reserve forward guidance. FRB Cleveland Working Paper, 18-15.

Mertens, K., Ravn, M.O., 2013. The dynamic effects of personal and corporate income tax changes in the united states. Am. Econ. Rev. 103 (4), 1212-1247.

Miranda-Agrippino, S., Ricco, G., 2018. The transmission of monetary policy shocks. CEPR Discussion Paper, No. 13396.

Rogers, J., Scotti, C., Wright, J., 2014. Evaluating asset-market effects of unconventional monetary policy: a multi-country review. Econ. Policy 29 (80), 749-799.

Stock, J.H., Watson, M.W., 2012. Disentangling the channels of the 2007-2009 recession. NBER Working Paper, 18094

Swanson, E., 2017. Measuring the effects of federal reserve forward guidance and asset purchases on financial markets doi:10.3386/w23311. NBER Working Paper, No. 23311.

Tenreyro, S., Thwaites, G., 2016. Pushing on a string: US monetary policy is less powerful in recessions. Am. Econ. J. 8 (4), 43-74. doi:10.1257/mac.20150016.

Wright, J.H., 2012. What does monetary policy do to long-term interest rates at the zero lower bound? Econ. J. 122 (564), F447-F466. 